\title{
Extremely large anthropogenic-aerosol contribution to total aerosol load over the Bay of Bengal during winter season
}

\author{
D. G. Kaskaoutis ${ }^{1}$, S. Kumar Kharol ${ }^{2,3}$, P. R. Sinha ${ }^{4}$, R. P. Singh $^{5}$, H. D. Kambezidis ${ }^{6}$, A. Rani Sharma ${ }^{2}$, and \\ K. V. S. Badarinath ${ }^{2}$ \\ ${ }^{1}$ Research and Technology Development Centre, Sharda University, Greater Noida - 201306, India \\ ${ }^{2}$ Atmospheric Science Section, Oceanography Division, National Remote Sensing Centre, Dept. of Space-Govt. of India, \\ Hyderabad - 500625 , India \\ ${ }^{3}$ Department of Physics and Atmospheric Science, Dalhousie University, Halifax, Canada \\ ${ }^{4}$ National Balloon Facility, Tata Institute of Fundamental Research, Hyderabad - 500 062, India \\ ${ }^{5}$ School of Earth and Environmental Sciences, Schmid College of Science and Technology, Chapman University, Orange, \\ CA 92866, USA \\ ${ }^{6}$ Atmospheric Research Team, Institute for Environmental Research and Sustainable Development, National Observatory of \\ Athens, Lofos Nymphon, 11810 Athens, Greece
}

Received: 26 December 2010 - Published in Atmos. Chem. Phys. Discuss.: 8 March 2011

Revised: 1 July 2011 - Accepted: 11 July 2011 - Published: 21 July 2011

\begin{abstract}
Ship-borne observations of spectral aerosol optical depth (AOD) have been carried out over the entire Bay of Bengal $(\mathrm{BoB})$ as part of the W-ICARB cruise campaign during the period 27 December 2008-30 January 2009. The results reveal a pronounced temporal and spatial variability in the optical characteristics of aerosols mainly due to anthropogenic emissions and their dispersion controlled by local meteorology. The highest aerosol amount, with mean $\mathrm{AOD}_{500}>0.4$, being even above 1.0 on specific days, is found close to the coastal regions in the western and northern parts of BoB. In these regions the Ångström exponent is also found to be high $(\sim 1.2-1.25)$ indicating transport of strong anthropogenic emissions from continental regions, while very high $\mathrm{AOD}_{500}(0.39 \pm 0.07)$ and $\alpha_{380-870}$ values $(1.27 \pm 0.09)$ are found over the eastern BoB. Except from the large $\alpha_{380-870}$ values, an indication of strong fine-mode dominance is also observed from the AOD curvature, which is negative in the vast majority of the cases, suggesting dominance of an anthropogenic-pollution aerosol type. On the other hand, clean maritime conditions are rather rare over the region, while the aerosol types are further examined through a classification scheme based on the relationship between $\alpha$ and $d \alpha$. It was found that even for the same $\alpha$ values the fine-mode dominance is larger for higher AODs showing the strong continental influence over the marine environment of
\end{abstract}

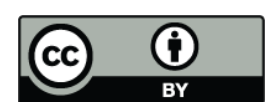

Correspondence to: S. Kumar Kharol (shaileshan2000@yahoo.co.in)
BoB. Furthermore, there is also an evidence of aerosol-size growth under more turbid conditions indicative of coagulation and/or humidification over specific $\mathrm{BoB}$ regions. The results obtained using OPAC model show significant fraction of soot aerosols ( $\sim 6 \%-8 \%)$ over the eastern and northwestern $\mathrm{BoB}$, while coarse-mode sea salt particles are found to dominate in the southern parts of BoB.

\section{Introduction}

In the last decades aerosols have been recognized as a major source in determining global climatic change, since they play an important role in solar and thermal radiative transfer in the atmosphere (e.g. Wild, 2009). Through their direct and indirect effects aerosols strongly modify the radiation budget at the earth's surface as well as the cloud microphysical properties, precipitation rate and hydrological cycle (e.g. Ramanathan et al., 2001a). The climatic effect of aerosols is closely related to their optical properties, surface albedo and their relative position in respect to that of clouds (e.g. Koch and Del Genio, 2010) and, as a consequence, the climate response to the different aerosol types varies significantly from negative (cooling) to positive (heating) still having large uncertainties (e.g. Satheesh and $\mathrm{Kr}$ ishna Moorthy, 2005 and references therein). Systematic records, either through long-term global observation networks over land (e.g. AERONET), intensive field campaigns

Published by Copernicus Publications on behalf of the European Geosciences Union. 
or from satellite monitoring can contribute to reducing uncertainty. Because of the aerosol sources and emission characteristics, atmospheric lifetimes and dynamic processes in the atmosphere, their physical and chemical characteristics are highly inhomogeneous in space and time even over oceanic areas (e.g. Smirnov et al., 2009). The aerosol optical and physico-chemical properties at a given location depend on the source region of aerosol formation and are modified by local and regional meteorology besides mixing with other particles of non-local origin (Madhavan et al., 2008). This information is useful for mitigation and emissions studies, for defining aerosol source strength and climate implications (e.g. Kaskaoutis et al., 2007a) and also for evaluating climate models, which simulate the transport of specific components, e.g. soot (Chin et al., 2009).

The aerosol-climate coupling and its global impact have attracted the attention of scientists mainly on densely populated and climatically sensitive areas, such as south Asia (e.g. Lawrence and Lelieveld, 2010 and references therein). Earlier studies (e.g. Menon et al., 2002; Lau et al., 2006; Gautam et al., 2009a) have revealed elevated absorbing aerosol layers, especially over the Indo-Gangetic plains (IGP), which contribute to the warming of troposphere as observed by Gautam et al. (2010). The warming of the troposphere may have direct or indirect impact on the early onset and shifting of the monsoon. During winter season (December to February; also called dry season), the mean wind pattern around Indian sub-continent is north-westerly and the continental aerosols transported over the nearby oceanic regions are of various origins and chemical compositions (e.g. George and Nair, 2008; Nair et al., 2008;), also presenting quite variable optical properties in spatial and temporal domains (e.g. Moorthy et al., 2010). They can be originated from both natural (sea-salt production, dust storms) and anthropogenic sources (fossil-fuel combustion, biomass burning) remaining in the marine atmosphere for few days to few weeks until they are deposited into the ocean by gravitational settling or rain washout (Kumar et al., 2010).

Recent cruise campaigns (e.g. Indian Ocean Experiment, INDOEX; Arabian Sea Monsoon Experiment, ARMEX; Integration Campaign for Aerosols, gases and Radiation Budget, ICARB) focused on region-specific characterization of the aerosol properties in oceanic regions surrounding India. Results from these campaigns have shown that large amounts of wind-blown dust particles and other anthropogenically produced aerosols get transported from the Asian landmass over oceanic regions, thousands of kilometers away from their sources (e.g. Ramanathan et al., 2001b; Ganguly et al., 2005; Moorthy et al., 2005, 2008). INDOEX aimed to study the advection of continental aerosols from adjacent landmass over to Indian Ocean, their radiative effects and the role of the Inter-Tropical Convergence Zone (ITCZ) in the aerosol transport. While INDOEX addressed these issues and focused on a north-south transect over the Arabian Sea (AS), the northern and western parts of AS as well as the entire $\mathrm{BoB}$ remained unexplored. ICARB campaign was carried over the BoB, AS and northern Indian Ocean (NIO) during the pre-monsoon season of 2006 to shed light on the spatial and temporal characteristics and dynamics of aerosols emitted from the continent; however, the far eastern $\mathrm{BoB}$, east of Andaman and Nicobar islands remained unexplored. To investigate the aerosol field in more detail the Winter-ICARB (W-ICARB) was scheduled from the Indian Space Research Organization Geosphere Biosphere Program (ISRO-GBP) to be conducted over BoB. Although BoB has been extensively studied by several researchers during the earlier ICARB campaign (special issue in J. Earth System Science and many other studies), the achievements of WICARB are: (i) this campaign was performed during a different season (December-January) when the synoptic winds are of continental origin, (ii) none of the earlier cruises covered the eastern part of $\mathrm{BoB}$ (beyond $\sim 93^{\circ} \mathrm{E}$ ), (iii) the interesting observations of high AOD and $\alpha$ values associated with a large fine-mode component in east $\mathrm{BoB}$ are brought out for the first time during W-ICARB.

The present study focuses on the AOD and Ångström exponent spectral variation and curvature, which can constitute the basis for the aerosol-type classification. Although earlier studies (e.g. Kalapureddy and Devara, 2008; Kedia and Ramachandran, 2009) presented some results of the spectral AOD curvature, this is the very first that discriminates the main aerosol types over $\mathrm{BoB}$ during winter season and the results are compared with those found over BoB and AS during pre-monsoon. Furthermore, the use of a classification scheme based on the relation between $\alpha$ and $d \alpha$ is applied for the first time over BoB showing promising results about the aerosol modification processes. The use of OPAC model for the simulation of the main aerosol properties over entire $\mathrm{BoB}$ is another unique topic of the present work, while our results were found to be in considerable agreement with optical and chemical aerosol characteristics measured on board by various scientific teams.

\section{Study region and campaign details}

$\mathrm{BoB}$ has a unique weather pattern in terms of the Indian monsoon and the associated winds show seasonal reversal; being surrounded by densely populated and industrialized regions at its north, west and east, provides an excellent environment for the investigation of natural marine aerosols as well as their interaction with continental ones (e.g. Moorthy et al., 2008), since pristine air masses from southern Indian Ocean and polluted air from Indian sub-continent meet. The prevailing meteorological conditions during W-ICARB consist of generally clear skies with north-westerly winds in west and north BoB, while easterly winds of higher intensity were observed over east and parts of south BoB (Raghavendra Kumar et al., 2011; Sinha et al., 2011a), which is a typical winter season flow. W-ICARB was conducted from 


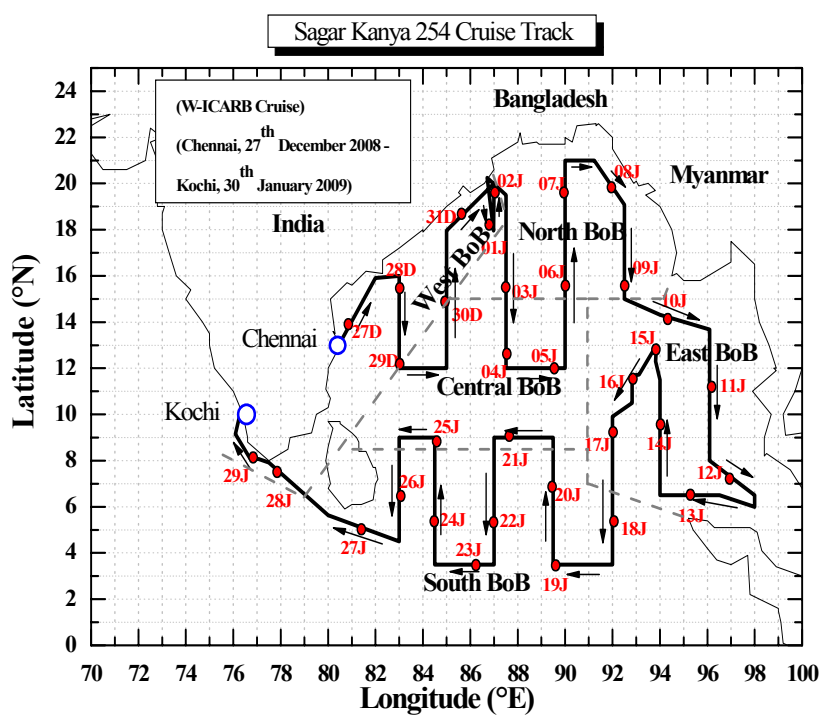

Fig. 1. The cruise track of Sagar Kanya 254 during W-ICARB, 27 December 2008-30 January 2009. The arrow shows the ship's direction of movement, while the circles the positions of the ship at 10:30 LST for each day defined in red next to the circles. The entire BoB is divided in 5 sub-regions, namely (a) west, along the Indian coast, (b) north, (c) east, (d) central, and (e) south.

27 December 2008 to 30 January 2009 over entire BoB focusing on the physical and optical properties of atmospheric aerosols, trace gases and aerosol chemistry over the region. The cruise track during the campaign is shown in Fig. 1. The arrowheads denote the direction of the ship movement, while the red circles show the mean position of the ship at 10:30 local time (LT) on each day. The oceanic research vessel (ORV) Sagar Kanya started from Chennai port $\left(13.1^{\circ} \mathrm{N}\right.$, $\left.80.2^{\circ} \mathrm{E}\right)$, a metro city in the southeastern coast of India on 27 December 2008, and during its return journey, passed Sri Lanka on 28 January 2009 and returned back to Kochi $\left(9.6^{\circ} \mathrm{N}, 76.1^{\circ} \mathrm{E}\right)$ at $\mathrm{AS}$ on 30 January 2009 . The intense field phase covered the longitudinal sector $80^{\circ} \mathrm{E}-97^{\circ} \mathrm{E}$ with a latitudinal coverage from $3^{\circ} \mathrm{N}$ to $20^{\circ} \mathrm{N}$. The particular configuration of the cruise track enabled measurements on the coastal waters and oceanic regions in rapid succession (Moorthy et al., 2010). This provided a nearly homogeneous spatially gridded aerosol database within a time span of about a month, during which the aerosol characteristics were not significantly changed. This was also corroborated by the prevailing meteorology, which was devoid of any major synoptic weather systems, such as cyclones, depressions or extensive cloud cover during the measuring period.

\section{Ship-borne measurements and methodology}

During the W-ICARB campaign plenty of instrumentation was in operation on board ORV by several scientific teams focusing on investigating the aerosol optical, physical and chemical properties. Some of the initial results of the campaign have been recently published emphasizing on several columnar and surface aerosol characteristics, such as the spatial distribution of AOD, Ångström exponent, accumulation fraction, sub-micron and super-micron particles, the vertical aerosol profiles and the chemical composition of the aerosols (Moorthy et al., 2010; Kumar et al., 2010; Raghavendra Kumar et al., 2011; Sinha et al., 2011a, b), while several other studies are under submission (M. Gogoi, M. Sarin, personal communication, 2011). In the present study, we have used the spectral AOD measurements collected by our group and model simulated results. High temporal resolution $(\sim 10 \mathrm{~min})$ observations of direct-beam solar radiation were made using two (sun-photometer and ozonometer) handheld MICROTOPS-II, (MT) (Solar Light Company, USA). One provided AOD at 5 channels (380, 440, 500, 675 and $870 \mathrm{~nm}$ ), while the other AOD at $1020 \mathrm{~nm}$, columnar water vapor (CWV) and column ozone, using three UV and two IR bands, with one of them at $1020 \mathrm{~nm}$. The Full Width at Half Maximum (FWHM) bandwidth for 380-nm channel is $2.4 \pm 0.4 \mathrm{~nm}$ and $10 \pm 1.5$ for other channels. The accuracy of the sun-targeting angle is better than $0.1^{\circ}$, while the field of view (FOV) 2.5o. The sun-photometer provides optical depths by knowing the respective radiation intensities at topof-atmosphere (TOA), using its internal calibration. The errors in the AOD estimations were found to be well below, or equivalent, to \pm 0.03 (Morys et al., 2001) with larger values in the UV, while errors from the subtraction of Rayleigh component, ozone and water-vapor absorption are about one order of magnitude lower (Kaskaoutis and Kambezidis, 2006). As discussed by Kaskaoutis et al. (2010), we followed the method outlined by Cachorro et al. (2004) for correction of AOD at each wavelength in order to eliminate the diurnal artifact of AOD. Shaw (1980) reported anomalous absorption at $1010 \mathrm{~nm}$, possibly from water vapor, since the extinction at this wavelength increases with increasing CWV. The watervapor absorption also affects the 1020-nm channel increasing the measured AOD. Despite that, there is another possible uncertainty associated with the $1020-\mathrm{nm}$ channel due to the temperature-sensitivity of the silicon detector, which is insignificant at the other wavelengths. For these reasons, the 1020-nm channel was excluded from the analysis. The MT was factory calibrated at regular intervals, while the details about its design, calibration, and performance have been described elsewhere (Morys et al., 2001; Porter et al., 2001; Ichoku et al., 2002). Triplet observations with the MT were made at every 10 minutes to avoid any possible manual error in sun pointing on the moving platform. To further eliminate such errors the instrument was operated by the same observer throughout the cruise period. Furthermore, data recorded around cloud passage or near the FOV of the instrument were not considered for analysis. A Global Positioning System (GPS) receiver attached to the sun-photometer provided information about time, location and altitude. Intense care has been taken to avoid contamination from the 
(a)

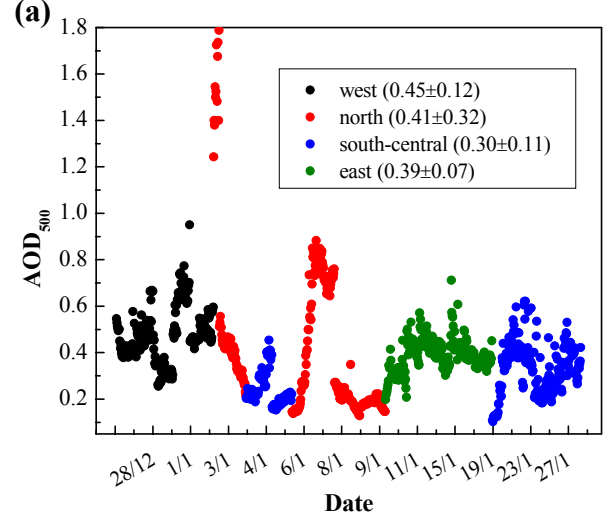

(b)

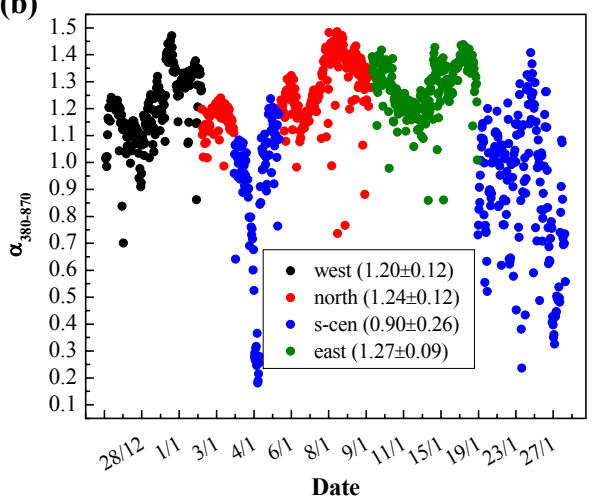

Fig. 2. Temporal variation of $\mathrm{AOD}_{550}$ (a) and $\alpha_{380-870}$ (b) values over different $\mathrm{BoB}$ sub-regions during W-ICARB cruise campaign. The mean values along with the standard deviations are given for each sub-region.

unfavorable smoke and other exhausts from the chimney of the ship operating the instrument in the upwind direction of the ORV and when this was not the case the measurements stopped. Due to cloud formations on some of the cruise days, the number of available spectra varied widely, from 3 (on 18 and 22 January) to above 50 (on 1, 3, 4, 8, 9 and 17 January). Also, some days $(13,28-30$ January) were absolutely overcast obscuring the sun-photometer measurements. From the available dataset, we also removed those spectra, which resulted to large typical errors when fitting a $2^{\text {nd }}$ order polynomial to the log-log plot of the spectral AOD (Eq. 1), setting a threshold in $\mathrm{R}^{2}$ value of 0.92 . Such data may contain cloud contamination and with this limitation we avoid large errors in the computations of $a_{1}, a_{2}, \alpha$ and $d \alpha$. Our spectral AOD measurements were validated (correlation of 0.95) against those reported by Moorthy et al. (2010) posted on the MAN web site (http://aeronet.gsfc.nasa.gov/new_web/ cruises_new/Sagar_Kanya_09.html).

The Ångström formula has been fitted in spectral AODs in order to obtain the wavelength exponent $(\alpha)$ and the turbidity coefficient $(\beta)$ using the least-squares method in the $\ln A O D$ vs. $\ln \lambda$ plot in the spectral band $380-870 \mathrm{~nm}$. Using this method the error in $\alpha$ is found to be $\sim 0.025 \pm 0.002$, while it slightly increases $(\sim 0.03)$ when the Volz method is applied in the spectral band $675-870 \mathrm{~nm}$. The accuracy in the AOD retrievals leads to uncertainties in $\alpha$ and $d \alpha$ values, used in various parts of the manuscript, of lower than $\sim 8 \%$. The curvature of the $\ln A O D$ vs. $\ln \lambda$ was also used to have some insight on the aerosol-size distribution and fineto-coarse mode dominance (Eck et al., 1999; Schuster et al., 2006; Kaskaoutis et al., 2007b). The curvature is characterized by the coefficient $a_{2}$ (Eq. 1), which can be utilized in conjunction with AOD and $\alpha$ for the discrimination of different aerosol types (Eck et al., 1999):

$\ln \mathrm{AOD}_{\lambda}=a_{2}(\ln \lambda)^{2}+a_{1} \ln \lambda+a_{0}$
In the present analysis, Eq. (1) was applied to the measured AODs at 5 wavelengths $(380,440,500,675$ and $870 \mathrm{~nm})$ for better quantification of the uncertainties in the simulations, despite that the 2 nd-order polynomial fit requires three wavelengths for its application.

\section{Results}

\subsection{Temporal variation of the aerosol optical properties}

Figure 2 shows the temporal variation of $\mathrm{AOD}_{500}$ (a) and $\alpha_{380-870}(\mathrm{~b})$ over BoB during W-ICARB dividing the whole set of measurements into four $\mathrm{BoB}$ sub-regions, i.e. west, north, south-central and east (see Fig. 1). High AOD is observed near the coasts (27-28 December, 1-2 and 7 January) and it was found to decrease when the ship moves away from the shore with lower values over pristine ocean (4-5 and 19-20 January). The large day-to-day variability could be due to aerosol emissions from the Indian sub-continent and to the prevailing meteorological conditions (Moorthy et al., 2010). The high $\mathrm{AOD}_{500}$ values close to the coast arise mainly from the anthropogenic activities along the coastal regions, which are highly urbanized and industrialized. As the anthropogenic aerosols are generally in the sub-micron size and hence have longer residence times, they get transported to greater distances over the ocean before they settle down under gravity. Extremely large $\mathrm{AOD}_{500}$ values $(>1.2)$ were found in the morning hours of 2 January when the ship was cruising in the northern most region of BoB. Special care has been taken in order to secure that these data were not cloud contaminated. This is justified by the high $\alpha$ values and the accuracy of the polynomial fit (Eq. 1). A secondary peak in $\mathrm{AOD}_{500}$ is observed on 7 January when the ORV approaches again the northern coast of $\mathrm{BoB}$. The mean $\mathrm{AOD}_{500}$ in the western part of $\mathrm{BoB}$ is found to be $0.45 \pm 0.12$, which is comparable to that found in the same region $(\mathrm{AOD}=0.41 \pm 0.14)$ during a short cruise in February 2003 (Vinoj et al., 2004). 
Similar $\mathrm{AOD}_{500}(0.44-0.50)$ over this area was reported during W-ICARB by other studies (Moorthy et al., 2010; Raghavendra Kumar et al., 2011). The $\mathrm{AOD}_{500}$ in west and north $\mathrm{BoB}$ is comparable in magnitude with that found during winter season over Hyderabad (Kaskaoutis et al., 2009) and over 4 urban Indian cities (Ramachandran, 2007) indicating strong influence of these regions from the coastal urban centers. The mean $\mathrm{AOD}_{500}$ over south-central $\mathrm{BoB}$ $(0.30 \pm 0.11)$ is found to be lower than that of the other subregions and comparable to that $(0.26 \pm 0.10)$ observed over southern BoB and NIO during ICARB-06 (Kalapureddy and Devara, 2008); similar values $(0.29 \pm 0.05)$ are reported by Raghavendra Kumar et al. (2011) over these regions. East $\mathrm{BoB}$ shows a narrow $\mathrm{AOD}_{500}$ distribution, since $\sim 84 \%$ of the values lie in the range $0.3-0.5$. Such a high $\mathrm{AOD}_{500}$ value $(0.39 \pm 0.07)$ over far east $\mathrm{BoB}$ is found for the first time, since this region was remained unexplored during the former ICARB campaign. However, similar AODs were found over Port Blair associated with air masses from southeast Asia (Moorthy et al., 2003), where extensive biomass burning occurred during W-ICARB. The mean $\mathrm{AOD}_{500}$ over entire $\mathrm{BoB}$ was found to be $0.39 \pm 0.20$, which is comparable to that $(0.36 \pm 0.12)$ during ICARB-06 and much higher than that found over AS during several previous cruises (e.g. Ramanathan et al., 2001b; Moorthy et al., 2005; Kalapureddy and Devara, 2008).

The time series of $\alpha$ shows large day-to-day variability with a sharp gap on 4 January when the ship was cruising central BoB. These low $\alpha$ values are found to be mainly associated with coarse sea-salt aerosols over the area (Kumar et al., 2010). Large scatter and diurnal variation in $\alpha$ values is observed in south-central BoB associated with the lowest $\mathrm{AOD}_{500}$, which was also observed by Rajeev et al. (2000) and Dey and Singh (2002) using satellite data. The anthropogenic aerosols from fossil-fuel and bio-fuel combustion contribute to fine particles in winter, thus $\alpha>1$ in the vast majority of the cases. During this season the marine atmospheric boundary layer (MABL) is found to be shallow and traps pollutants in a smaller volume leading to large finemode fraction near the surface (Raghavendra Kumar et al., 2011). Moorthy et al. (2010) observed high accumulationmode mass concentrations within the MABL over the entire $\mathrm{BoB}$ with accumulation fraction ranging from 0.6 to 0.95 , whereas very high fine-mode aerosol mass fractions $(\sim 0.8)$ were observed over the northeastern and western coastal $\mathrm{BoB}$. The lower temperatures along with the trapping of pollutants favor the formation of hazy and foggy conditions over IGP (Ganguly et al., 2006; Das et al., 2008; Badarinath et al., 2009a) that influence the head BoB during favorable wind conditions. Thus, large amount of mixed continental aerosols and Black Carbon (BC) over $\mathrm{BoB}$ was found to be associated with air masses originating from IGP (Kumar et al., 2010). The mean $\alpha$ over entire $\mathrm{BoB}$ is $1.14 \pm 0.23$, which is in close agreement with the values $(1.21 \pm 0.11,1.1 \pm 0.1)$ found over BoB in pre-monsoon (Kalapureddy and Devara, 2008) and winter (Vinoj et al., 2004), respectively. The largest mean $\alpha$ is observed over east $\mathrm{BoB}$ indicating that this region is strongly affected by fine-mode aerosols coming from south-eastern Asia. The $\alpha$ values shown for the different BoB sub-regions (Fig. 2b) are in close agreement to those found by others (Moorthy et al., 2010; Raghavendra Kumar et al., 2011) even for slight different sub-regions and wavelength bands. Unlike the other marine environments where sea-salt aerosols contribute most to the total aerosol mass concentration (e.g. Smirnov et al., 2009), the aerosol chemical composition analysis performed over Indian Ocean and Kaashidhoo during INDOEX 1999 found that sea salt contributes only $11 \%$ and $17 \%$ to the total aerosol loading, respectively, while anthropogenic aerosols contribute the most (Ramanathan et al., 2001b; Satheesh et al., 2002). The chemical analysis during W-ICARB shows a large fraction of anthropogenic nss- $\mathrm{SO}_{4}^{2-}$, organic matter and $\mathrm{BC}$ in the aerosolmass concentrations (Kumar et al., 2010). This fact partly explains the high $\alpha$ values over BoB. The spatial distribution of AOD and $\alpha$ over BoB during W-ICARB are presented elsewhere (Moorthy et al., 2010; Raghavendra Kumar et al., 2011) showing great consistency with our results.

Figure 3 shows the temporal variation of the $a_{2}$ values (a) and the associated errors (b) from the 2 nd order polynomial fit. Larger negative values of $a_{2}$ correspond to a relative influence of fine-mode vs. coarse-mode aerosols (Eck et al., 1999), while values near to zero correspond to aerosolsize distribution with similar contribution of fine and coarse modes (Eck et al., 2005). In contrast, positive $a_{2}$ values suggest dominance of natural coarse-mode aerosols. During WICARB, the curvature $\left(a_{2}\right)$ shows mostly negative values indicating significant contribution of fine-mode aerosols over entire BoB with exception of some parts (mainly in southcentral and secondarily in north). The aerosol properties in the open oceanic regions are influenced by in-situ production of sea spray, which depends on wind speed (e.g. Satheesh et al., 2006), while those near coasts are influenced by the continental outflow. The $a_{2}$ values exhibit a similar range $(\sim-0.8$ to 0.8 ) to that found over AS (Kaskaoutis et al., 2010) but with larger fraction of negative values, as also observed over $\mathrm{BoB}$ during pre-monsoon season (Kalapureddy and Devara, 2010). The percentages for $a_{2}>0$ are $1.5 \%, 27.7 \%, 36.5 \%$ and $5.7 \%$ for west, north, south-central and east BoB, respectively. The larger presence of coarse-mode aerosols in south-central BoB is associated with enhanced values of $\mathrm{RH}$ and stronger winds (Sinha et al., 2011b). Larger errors in $a_{2}$ are found over regions with low $\mathrm{AOD}_{500}$ (parts of centralsouth and northeastern $\mathrm{BoB}$ ) and are slightly lower than those found over AS (Kaskaoutis et al., 2010). On the other hand, low errors are found over west, north and east BoB, closely associated with high AODs, similarly to the results obtained over AS.

According to Schuster et al. (2006), $\alpha$ is equal to the difference $a_{2}-a_{1}$ to a first approximation. The correlations between $\alpha_{380-870}$ and $a_{2}-a_{1}$ (in the same spectral band) are 
(a)

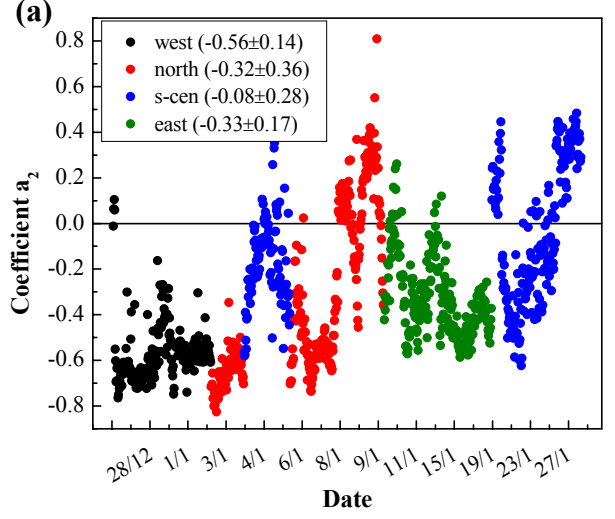

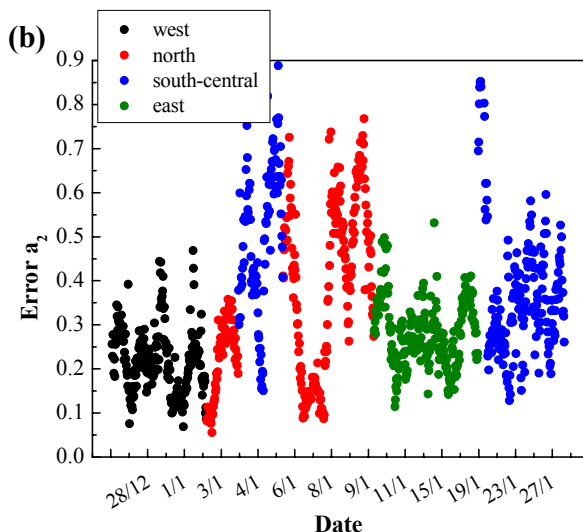

Fig. 3. Temporal variation of the coefficient $a_{2}$ (a) and its error (b) values over different BoB sub-regions during W-ICARB cruise campaign. The mean $a_{2}$ values along with the standard deviations are given for each sub-region.

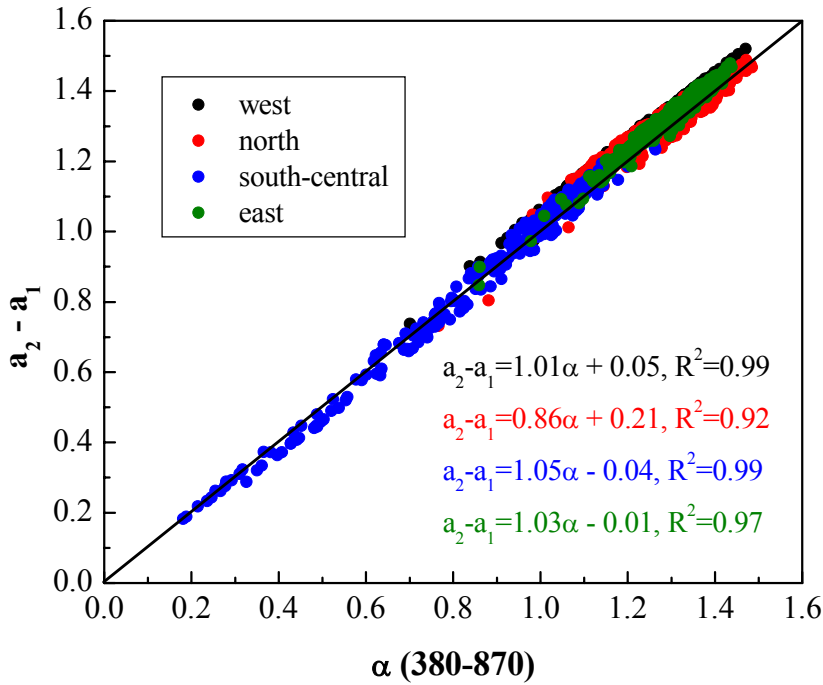

Fig. 4. Correlation between $\alpha_{380-870}$ and $a_{2}-a_{1}$ in the 4 BoB subregions. The linear relations for each region are shown in separate color.

shown in Fig. 4. The two parameters are strongly correlated in all BoB sub-regions; this supports the validity of the retrievals suggesting minimizing of errors in the computed parameters $\left(\alpha, a_{1}\right.$ and $\left.a_{2}\right)$. The few scattered points, especially in north $\mathrm{BoB}$, correspond to cases where the $2^{\text {nd }}$ order polynomial fit does not provide high accuracy $\left(\mathrm{R}^{2}<0.94\right)$. Thus, the dataset can be considered as valid for the applications analyzed in the next sections.

\subsection{Classification of aerosol types via sun-photometer measurements}

The characterization of aerosol types requires information on several optical and physical properties that depend strongly on wavelength (e.g. Dubovik et al., 2002). The combined use of properties corresponding to aerosol load (e.g. AOD) and aerosol size (e.g. Ångström exponent, effective radius, finemode fraction) is the most common and widely used technique for the discrimination between different aerosol types (e.g. Pace et al., 2006; Kaskaoutis et al., 2007a; El-Metwally et al., 2008; Carmona and Alpert, 2009; Kalapureddy et al., 2009). Thus, scatter plots of AOD vs. $\alpha$ can be obtained in order to discriminate different aerosol types through determination of physically interpretable cluster regions.

Figure 5 shows the scatter plot (left panel) and the density plot (right panel) of $\mathrm{AOD}_{500}$ vs. $\alpha_{380-870}$ over the entire BoB. The density plot was constructed using 0.1 step for both $\mathrm{AOD}_{500}$ and $\alpha_{380-870}$ values. There is a wide range of $\alpha_{380-870}$ values for low-to-moderate $\operatorname{AOD}_{500}(<0.4)$ suggesting large variability in the aerosol properties and type. The increasing values of $\alpha_{380-870}$ with increasing $\mathrm{AOD}_{500}$ in west $\mathrm{BoB}$ indicate significant contribution of fine particles in the atmospheric column, especially under high turbidity, results that are justified by sea-surface observations of finemode fraction (Moorthy et al., 2010). Similar feature has been observed elsewhere for a variety of fine-mode aerosols (e.g. Porter and Clarke, 1997; Remer et al., 1998; Reid et al., 1999). There is an evidence of reduction of $\alpha_{380-870}$ as AOD increases over east $\mathrm{BoB}$; this reflects the transition of fine-mode particles to accumulation-mode through coagulation, condensation and gas-to-particle conversion, results that are in agreement with Moorthy et al's (2010) observations, who reported larger accumulation that fine-mode fraction over eastern than over western BoB. A similar trend of decreasing values of $\alpha$ as AOD increases was observed over east Asia (Ogunjobi et al., 2004), AS (Kalapureddy et al., 2009) and other locations for various aerosol types (e.g. Eck et al., 1999; 2001; Pace et al., 2006). It is interesting to note that, except from south-central BoB where a large range of $\mathrm{AOD}_{500}$ vs. $\alpha_{380-870}$ exists, the other regions present similar $\mathrm{AOD}_{500}, \alpha_{380-870}$ pairs of maximum density. Viewing the density plot (right panel) a clear-defined area 

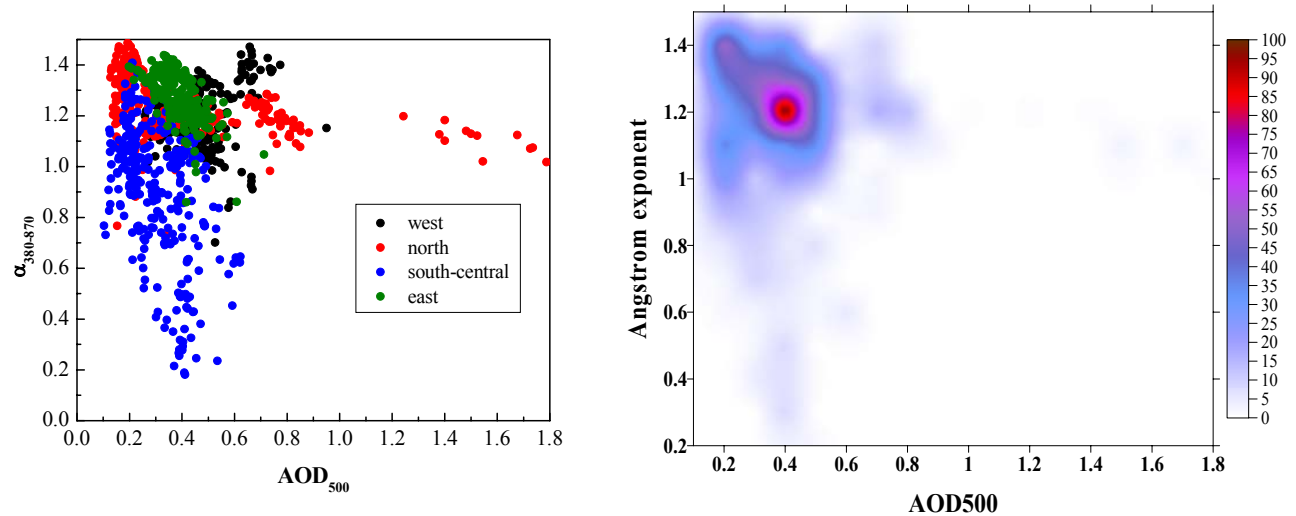

Fig. 5. Correlation between $\mathrm{AOD}_{500}$ and $\alpha_{380-870}$ in the different $\mathrm{BoB}$ sub-regions (left) and density plot of $\mathrm{AOD}_{500}$ vs. $\alpha_{380-870}$ correlation over entire BoB (right).

of larger density is revealed for the $\left(\mathrm{AOD}_{500}, \alpha_{380-870}\right)$ pair of $(\sim 0.4,1.2)$. This indicates that the aerosols over BoB during winter season are, in the vast majority of the cases, of anthropogenic origin with a large fine-mode fraction under turbid atmospheres. Other secondary large-density areas are those of $\left(\mathrm{AOD}_{500}, \alpha_{380-870}\right)=(\sim 0.2,1.4)$ corresponding to fine-mode aerosols for relative clean atmospheres and some hints of $\alpha_{380-870}<0.8$ for $\mathrm{AOD}_{500}=0.4-0.5$, indicative of coarse-mode particles under turbid conditions. The density plot over BoB in winter season is far away from that observed over AS during pre-monsoon (Kalapureddy et al., 2009) where four clearly defined maximum density regions were found, each corresponding to different aerosol type. On the other hand, the density plot over BoB is similar to that observed over urban Hyderabad during winter (Kaskaoutis et al., 2009), where the dominant aerosol type was defined from the $\left(\mathrm{AOD}_{500}, \alpha_{380-870}\right)$ pair of $(\sim 0.4-0.5,1.2)$. This indicates the strong influence of the anthropogenic emissions, which were found to have a spatial offshore extent of $\sim 400$ km over BoB (Moorthy et al., 2008).

For the classification of aerosols into specific types some "appropriate" threshold values are required. For a direct comparison with the previous study over AS (Kalapureddy et al., 2009) the threshold values remained the same, despite the striking differences between $\mathrm{BoB}$ and $\mathrm{AS}$ aerosols. Thus, (i) values of $\mathrm{AOD}_{500}<0.15$ with $\alpha_{380-870}<1.3$ represent Background Maritime (BM) conditions, (ii) $\mathrm{AOD}_{500}>0.2$ and $\alpha_{380-870}>1.0$ can characterize transported Anthropogenic Pollution and/or biomass-burning aerosols (AP), (iii) $\mathrm{AOD}_{500}>0.25$ associated with $\alpha_{380-870}<0.7$ are indicative of coarse-mode particles (sea salt, suspended dust) under turbid atmospheres (HCM), (iv) the remaining cases not belonging to any of the above groups are characterized as mixed-undetermined aerosols (MU). According to the analysis the contribution of each aerosol type over entire $\mathrm{BoB}$ is AP: 689 (70\%), BM: 25 (2.5\%), HCM: 55 (5.6\%) and MU: $217(22 \%)$. It should be noted that this classification must be considered only qualitatively, i.e. highlighting the large anthropogenic component over BoB, and not quantitative, since the percentages may be strongly modified with a change in the $\mathrm{AOD}_{500}, \alpha_{380-870}$ threshold values.

Figure 6 shows the percent contribution of the four aerosol types to the BoB sub-regions. The AP type is the most dominant with varying magnitudes ranging from $33 \%$ to $99 \%$. These fractions are larger than the respective found over AS (Kalapureddy et al., 2009) and Hyderabad (Kaskaoutis et al., 2009) rendering BoB to be a strong anthropogenicallypolluted region. The presence of HCM type (18.9\%) is limited over south-central BoB with an almost absence over the other regions. A pronounced difference between AS and $\mathrm{BoB}$ is the extremely large occurrence of AP type over east BoB $(99 \%)$, whereas in far AS its presence was limited. This is attributed to the different land use in the adjoining coasts. The eastern BoB is influenced by the densely populated southeast Asia with large urban and biomass-burning emissions in the dry period of the year, while far AS is close to arid Arabian Peninsula and the effect of anthropogenic pollution is limited. The most exciting finding of the present analysis is the relatively low fraction of MU, which was the dominant type in all of the above-mentioned studies. The large impact of the anthropogenic sources is further verified via chemical analysis that shows a widespread depletion of chloride in $\mathrm{PM}_{10}$, from 40 to $100 \%$, compared to $\mathrm{Cl}^{-} / \mathrm{Na}^{+}$ ratio in sea salt (Kumar et al., 2010). Furthermore, the carbonaceous aerosols (organic and elemental carbon) contribute $\sim 27 \%$ to $\mathrm{PM}_{2.5}$, while their significant linear regression with $\mathrm{K}^{+}$suggests biomass burning as their dominant source (bio-fuels, fossil fuels and agricultural waste). The outflow from southeast Asia exhibited enhanced fractional solubility of aerosol $\mathrm{Fe}$, associated with the lower abundance of dust and nss- $\mathrm{SO}_{4}^{-2}$. These observations suggest the dominance of combustion sources (biomass burning and fossil fuel) in dictating the aerosol iron solubility, especially over eastern BoB (Kumar et al., 2010), thus justifying the highest 

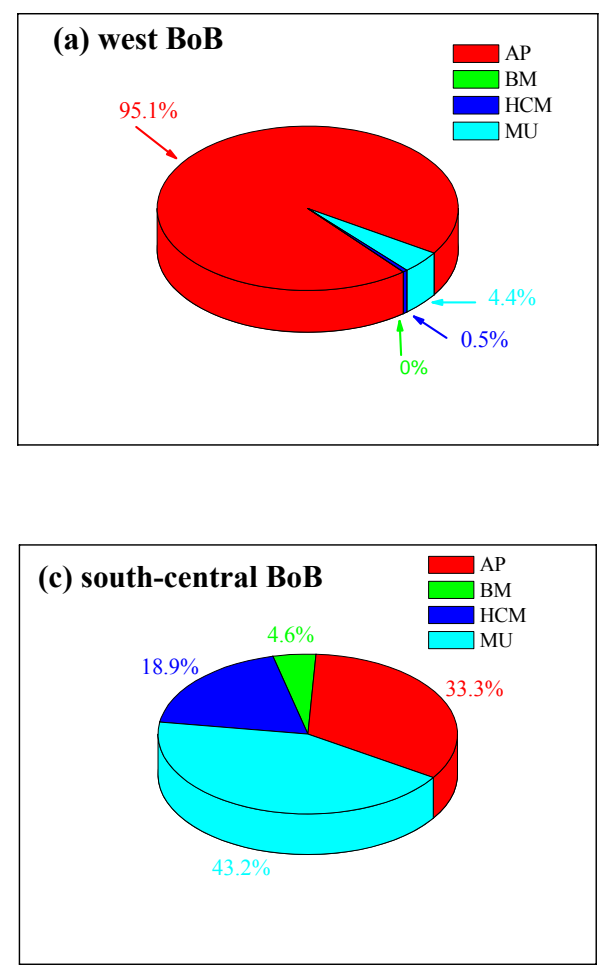
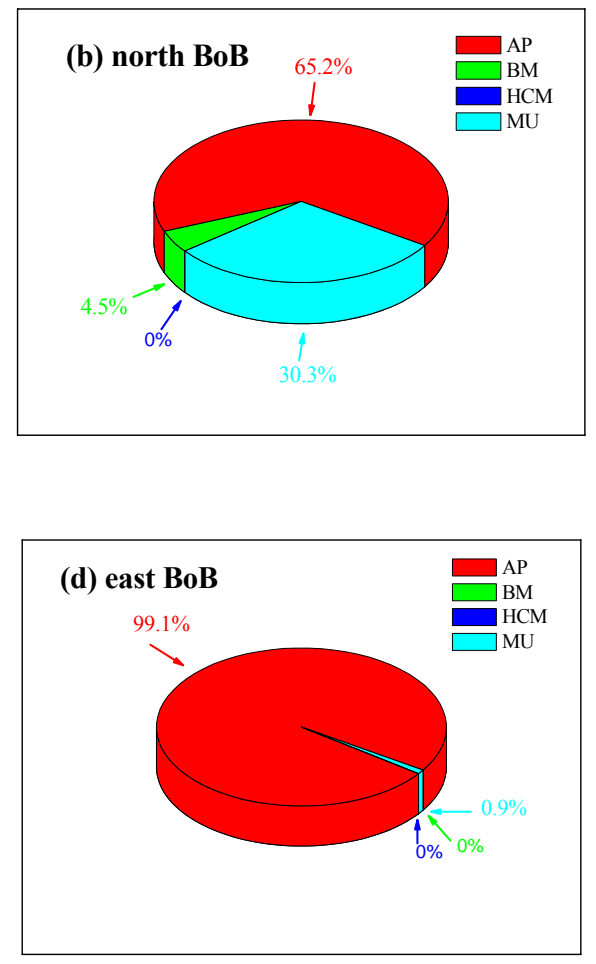

Fig. 6. Fraction pies of each aerosol type over the four BoB sub-regions during W-ICARB: AP (Anthropogenic Pollution, biomass burning included), BM (Background Maritime), HCM (Coarse-Mode for High turbid conditions), MU (Mixed-Undetermined).

AP fraction found over the region. The chemical analysis also showed that the highest AODs in west and north $\mathrm{BoB}$ are associated with large fraction of nss- $\mathrm{SO}_{4}^{-2}$, establishing anthropogenic dominance, as well as water-soluble Fe characteristic of dust deposition over the oceanic region. The dust mass fraction from the IGP outflow over north BoB was found to be $36 \%$ in the $\mathrm{PM}_{10}$ size, whereas it was $24 \%$ over south and eastern BoB from southeast Asian outflow and marine air masses (Kumar et al., 2010). It is, therefore, concluded that the mineral dust mixed with pollution may has influence to the large fraction of MU aerosols (30\%) over north $\mathrm{BoB}$, while the HCM aerosols over south $\mathrm{BoB}$ are mainly composed of large sea-salt particles and only hints of dust. On average, $\mathrm{nss}^{-\mathrm{SO}_{4}^{-2}}$ constitutes $\sim 65 \%$ of the total watersoluble ionic species and is primarily associated with finemode aerosols. The relatively high fraction of AP aerosols over south $\mathrm{BoB}$ is in agreement with the large anthropogenic component found over the region during ICARB campaign (Nair et al., 2010). Similarly, the anthropogenic contribution to the 5-yr (1996-2000) mean AOD over coastal AS was found to be above $90 \%$ and it was $74 \%$ over tropical Indian Ocean during the northeast monsoon season (Ramachandran, 2004). Ramanathan et al. (2001b) found that over NIO the human-produced contribution to the $\mathrm{AOD}_{500}$ was about $80 \pm 10 \%$. Satheesh et al. (1999) estimated that during INDOEX 1998 the anthropogenic aerosols contributed about

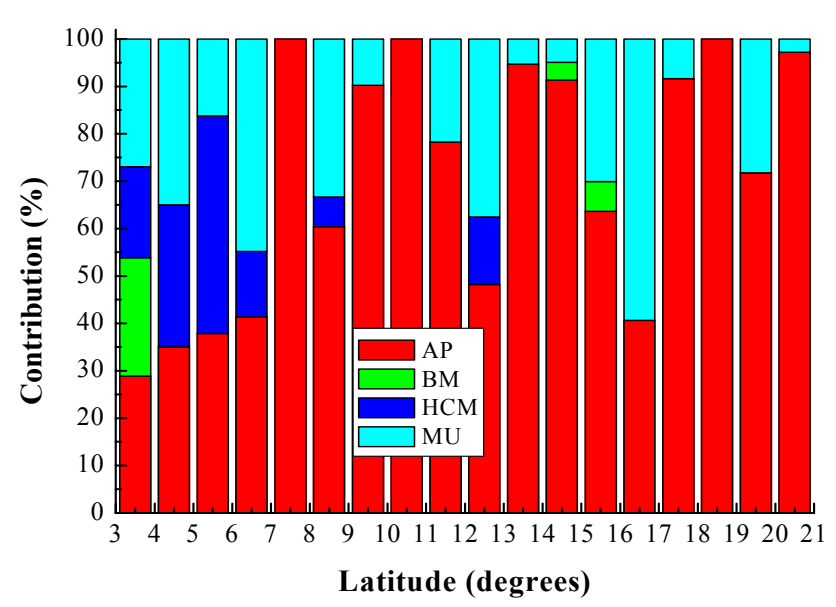

Fig. 7. Contribution (\%) of the four aerosol types according to the latitude over BoB during W-ICARB.

$65 \%$ to $\mathrm{AOD}_{500}$, while their contribution during INDOEX 1999 was more than $70 \%$ (Satheesh et al., 2002).

The contribution of the different aerosol types can be strongly modified exhibiting latitudinal and longitudinal variability of AOD and $\alpha$ (Kedia and Ramachandran, 2008). Figure 7 shows the latitudinal variation of the contribution (\%) of the four aerosol types. The results show that except 

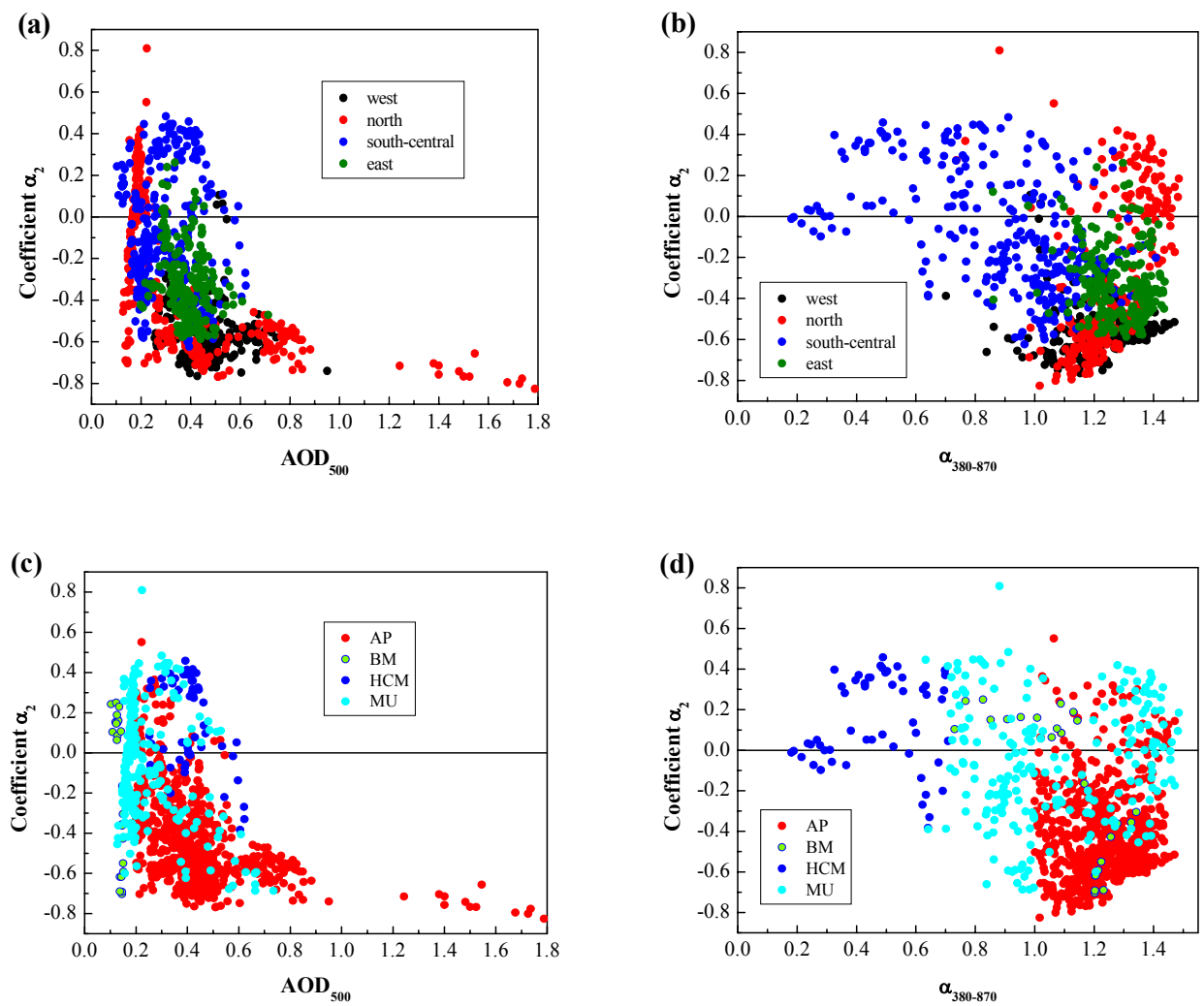

Fig. 8. Correlations between curvature (coefficient $a_{2}$ ) and $\mathrm{AOD}_{500}$ and $\alpha_{380-870}$ for the four $\mathrm{BoB}$ sub-regions (a, b) and for the four aerosol types $(\mathbf{c}, \mathbf{d})$, respectively.

for a few latitudinal belts the aerosol field over BoB during winter season is characterized by anthropogenic aerosols with the co-existence of mixed aerosols with fraction of $30 \pm 10 \%$ for the most latitudinal belts. In general, BM conditions are observed for $<4^{\circ} \mathrm{N}$ with some hints in central BoB $\left(14-16^{\circ} \mathrm{N}\right)$, while coarse-mode aerosols for $<7^{\circ} \mathrm{N}$. In the northern latitudes the AP type clearly dominates as well as for the latitudinal belt $9-12^{\circ} \mathrm{N}$ that corresponds to observations in east $\mathrm{BoB}$. The southern $\mathrm{BoB}$ is the most heterogeneous area regarding the aerosol type; as the latitude increases the aerosol field is composed nearly exclusively of AP aerosols. These results are in line with observations of increasing AOD, $\alpha$ and accumulation mass fraction at the northern latitudes of BoB (Moorthy et al., 2010). The respective graph (not shown) regarding the longitudinal variation did not show such clear findings, except of the larger fraction of AP for eastern longitudes.

Figure 8 shows the correlation of the coefficient $a_{2}$ against $\operatorname{AOD}_{500}(\mathrm{a}, \mathrm{c})$ and $\alpha_{380-870}(\mathrm{~b}, \mathrm{~d})$ for the four BoB subregions and the four aerosol types. The curvature can be utilized in conjunction with AOD and $\alpha$ for the discrimination of different aerosol types and enhance the knowledge about the volume fraction and effective radius of the fine-mode aerosols at intermediate values of $\alpha$ (Schuster et al., 2006). The data lying on or near the $a_{2}=0$ line correspond to the
Junge power law size distribution (without curvature) and occur for a wide range of $\mathrm{AOD}_{500}(0.2-0.6)$ and $\alpha_{380-870}(0.2-$ 1.4). For low $\mathrm{AOD}_{500}$ there is a wide variability in $a_{2}$ (both positive and negative), while for larger AODs $a_{2}$ becomes negative. The $\mathrm{AOD}_{500}$ vs. $a_{2}$ plot over $\mathrm{BoB}$ is very different than that found over AS (Kalapureddy et al., 2009). The main differences can be detected at the most negative $a_{2}$ values for high $\mathrm{AOD}_{500}$ over $\mathrm{BoB}$, while $a_{2}$ approaches zero for high $\mathrm{AOD}_{500}$ over AS. The former is indicative of enhanced presence of fine-mode aerosols in turbid atmospheres, while the latter of a bimodal aerosol-size distribution where the coarsemode has a significant fraction (e.g. Eck et al., 1999). The AP type exhibits mostly negative $a_{2}$ values, while for the BM and HCM types $a_{2}$ is mostly positive. Note also that the data obtained over northeast $\mathrm{BoB}\left(\mathrm{AOD}_{500}<0.2\right)$ are of $\mathrm{MU}$ type. For a specific value of $\alpha_{380-870}$, a large spread of $a_{2}$ occurs even for the same aerosol type. This is in agreement with the findings of Schuster et al. (2006); they have shown varying size distributions with the same $\alpha$ giving large differences in curvature and found that the curvature alone is not so capable for describing the aerosol particle size. However, it is possible to classify the aerosol types by plotting $\alpha_{380-870}$ vs. $a_{2}$. 
During pre-monsoon ICARB-06 Kalapureddy and Devara (2010) found coarse-mode dominance over BoB, NIO and $\mathrm{AS}$, with $\mathrm{BoB}$ to exhibit larger fine-mode fraction. The presence of much larger amount of fine-mode aerosols over BoB during winter season can be attributed to several reasons: (i) in this season the anthropogenic emissions (fossil-fuel combustion, BC emissions) are found to be large over India (Ramachandran and Rajesh, 2007; Pathak et al., 2010) and more specifically over IGP (Singh et al., 2004), the region which is the most responsible for the aerosol outflow over BoB (e.g. Dey and di Girolamo, 2010), (ii) the mineral and/or desert dust is more frequent over the region during pre-monsoon (e.g. Prospero et al., 2002; Gautam et al., 2009b), (iii) in west and north $\mathrm{BoB}$ there is a remarkable influence from elevated aerosol layers composed of coarse-mode particles during pre-monsoon (Nair et al., 2009), (iv) the coarse-mode aerosols have longer lifetime during pre-monsoon due to more stable atmospheric conditions, (v) eastern BoB, which is strongly influenced by fine-mode aerosols, was unexplored during ICARB-06 campaign.

Table 1 summarizes the aerosol optical properties obtained over BoB sub-regions for the four aerosol types. In general, $\mathrm{AOD}_{500}$ is found to be larger for the AP type, with exception of the MU type over west $\mathrm{BoB}$. This feature is also reversed over south-central $\mathrm{BoB}$ where $\mathrm{HCM}$ presents larger $\mathrm{AOD}_{500}$ and lower $\alpha_{380-870}$. It was found that for $\mathrm{AOD}_{500}>0.7 \mathrm{AP}$ is the only type that differentiates $\mathrm{BoB}$ from other marine locations, i.e. Lampedusa, Nauru (Pace et al., 2006; Kaskaoutis et al., 2007a). A striking feature is the large $\alpha_{380-870}$ values for the $\mathrm{BM}$ type over north $\mathrm{BoB}$; these data correspond to northeast $\mathrm{BoB}$, where the low $\mathrm{AOD}$, the large $\alpha$ and the dominance of fine-mode aerosols can be explained by air-mass trajectories and vertical aerosol distribution (Moorthy et al., 2010). The $a_{2}$ values can differentiate between coarse-mode (HCM and $\mathrm{BM}$ ) and fine-mode (AP, MU) aerosols having positive and negative values, respectively.

\subsection{Aerosol modification processes}

It is well known (e.g. Kaskaoutis and Kambezidis, 2008) that $\alpha$ depends strongly on the spectral bands used for its determination. Hence, the information contained in the $\mathrm{AOD}_{500}$ vs. $\alpha_{380-870}$ scatterplot (Fig. 5) becomes more difficult to interpret, while the spectral information given by the determination of $\alpha$ in different spectral bands helps us for classification of the aerosol types and examining aerosol modification. Gobbi et al. (2007) proposed a simple graphical method to visually convert $(\alpha, \mathrm{d} \alpha)$ to the contribution of fine aerosols to the AOD and the size of the fine particles. This classification scheme is based on Mie calculations (using air refractive index $m=1.4-0.001 i$ ) correlating the $\alpha$ vs. $d \alpha$ plot with the fine-mode fraction at $675 \mathrm{~nm}(\eta)$ and effective radius of fine aerosols $\left(R_{\mathrm{f}}\right)$ and is appropriate for identifying aerosol-modification processes, i.e. cloud contamination, hydration, and coagulation-aging. Gobbi et al. (2007)
Table 1. Mean and standard deviations of $\mathrm{AOD}_{500}, \alpha_{380-870}$ and coefficient $a_{2}$ values over the four BoB sub-regions corresponding to different aerosol types.

\begin{tabular}{lllll}
\hline Type & BoB region & AOD $_{500}$ & $\alpha_{380-870}$ & $a_{2}$ \\
\hline \multirow{4}{*}{ AP } & West & $0.467 \pm 0.117$ & $1.217 \pm 0.107$ & $-0.567 \pm 0.129$ \\
& North & $0.536 \pm 0.346$ & $1.217 \pm 0.09$ & $-0.480 \pm 0.281$ \\
& South-central & $0.292 \pm 0.084$ & $1.115 \pm 0.093$ & $-0.244 \pm 0.226$ \\
& EM & $0.389 \pm 0.07$ & $1.282 \pm 0.088$ & $-0.331 \pm 0.172$ \\
& West & - & - & - \\
& North & $0.146 \pm 0.004$ & $1.238 \pm 0.053$ & $0.031 \pm 0.277$ \\
& South-central & $0.125 \pm 0.01$ & $0.972 \pm 0.142$ & $0.157 \pm 0.059$ \\
& East & - & - & - \\
HCM & West & 0.526 & 0.697 & -0.387 \\
& North & - & - & - \\
& South-central & $0.410 \pm 0.09$ & $0.474 \pm 0.153$ & $0.145 \pm 0.221$ \\
MU & East & - & - & - \\
& West & $0.614 \pm 0.051$ & $0.932 \pm 0.052$ & $-0.544 \pm 0.248$ \\
& North & $0.187 \pm 0.07$ & $1.313 \pm 0.147$ & $-0.506 \pm 0.177$ \\
& South-central & $0.278 \pm 0.10$ & $0.922 \pm 0.142$ & $-0.089 \pm 0.224$ \\
& East & $0.419 \pm 0.169$ & $1.023 \pm 0.253$ & $-0.164 \pm 0.289$ \\
\hline
\end{tabular}

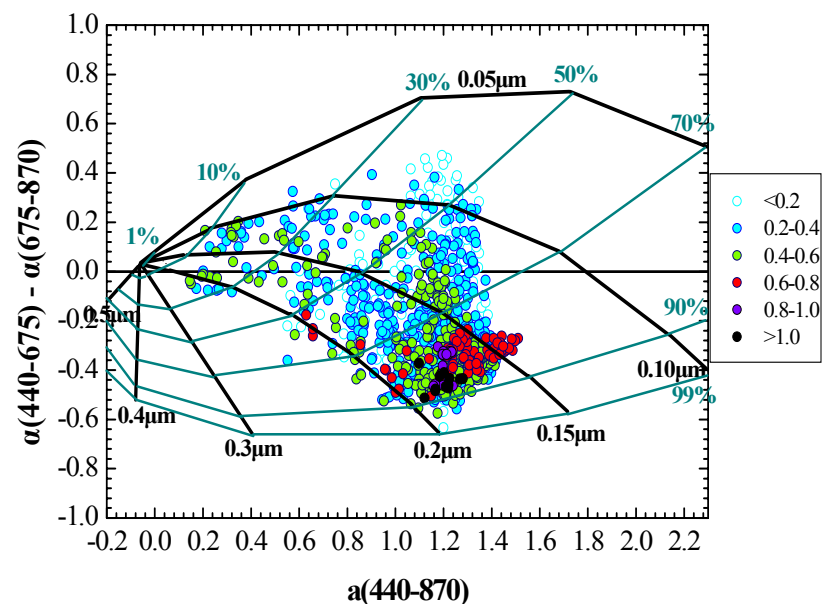

Fig. 9. Ångström exponent difference, $d \alpha=\alpha(440-675)-\alpha(675-$ 870 ), as a function of $\alpha_{440-870}$ and $\mathrm{AOD}_{500}$ (color scale) over entire BoB. The black lines indicate the $R_{\text {eff }}$ of fine-mode aerosols, while the cyan lines correspond to fine-mode fraction $(\eta)$.

showed the sensitivity of the classification scheme to refractive index. Computations indicated some clockwise rotation about the origin of the constant radius curves for increasing refractive index, while the effect is much weaker in the case of $\eta$. Maximum $R_{\mathrm{f}}$ indetermination is of the order of $\pm 25 \%$ for refractive index varying between $m=1.33-0.0 \mathrm{i}$ and $m=1.53-0.003 \mathrm{i}$, while the $\eta$ spans a range of the order of $\pm 10 \%$. Within this level of indetermination, the scheme is robust enough to provide an operational classification of the aerosol properties. This scheme is performed over entire BoB (Fig. 9) and its four sub-regions (Fig. 10), while recently it has been applied over AS during ICARB (Kaskaoutis et al., 2010) and over urban Athens by means of MFR data 

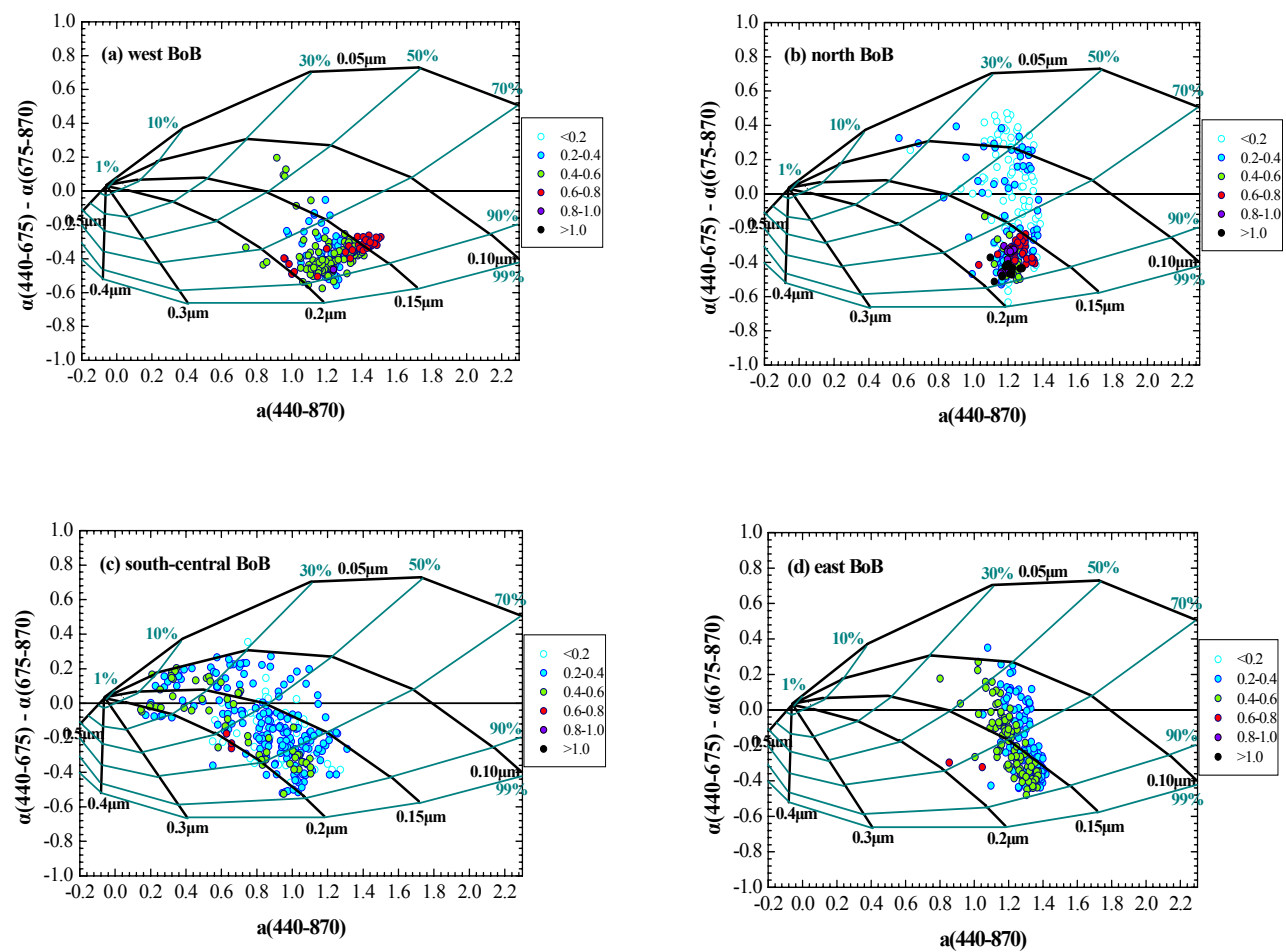

Fig. 10. Same as in Fig. 9, but for the four BoB sub-regions.

(Gerasopoulos et al., 2011). Gobbi et al. (2007) used only cases of AOD $>0.15$ from AERONET to avoid errors larger than $\sim 30 \%$. In the present analysis the whole set of observations was used since the fraction of $\mathrm{AOD}_{500}<0.15$ is very low $(\sim 3 \%)$. The Ångström exponent difference $(d \alpha)$ was defined as $\mathrm{d} \alpha=\alpha(440-675)-\alpha(675-870)$. In Figs. 9 and 10 the aerosols are classified by representing their $\mathrm{AOD}_{500}$ by different colors.

Negative $d \alpha$ indicates the dominance of fine-mode aerosols, while near zero or positive values correspond to aerosol-size distribution of two separate modes with the coarse one to have a large fraction. Regarding the entire $\mathrm{BoB}$, an increase in AOD shows a shift to larger $\alpha$ values (1.1-1.4) with $R_{\mathrm{f}}$ between $0.15-0.20 \mu \mathrm{m}$. The scheme indicates that the aerosols are of bimodal distribution with finemode fraction of $\sim 80 \%-90 \%$ for larger AODs. High aerosol extinctions over the BoB are linked to hygroscopic and/or coagulation growth from aging of the fine-mode aerosols leading to larger $R_{\mathrm{f}}(0.15-0.2 \mu \mathrm{m})$ and larger $\eta(80-90 \%)$ values. Fine-mode fraction below $50 \%$ occurs for moderate-tolow AODs over relative clean marine regions. Earlier studies over AS during pre-monsoon (Kalapureddy and Devara, 2010; Kaskaoutis et al., 2010) have shown a rather opposite feature, since for low AODs the fine-mode aerosols dominated; a complicated mixture of both anthropogenic pollution and mineral dust was found. These features are far from those observed over BoB during winter season.

The current emphasis is on obtaining a regional-scale characterization of the aerosol properties as well as mixing and modification processes; for this reason the same scheme is applied over the four BoB sub-regions (Fig. 10). Large differences in the $\alpha$ vs. $d \alpha$ plots are revealed establishing large heterogeneities in aerosol load, optical properties and modification processes over BoB. The aerosols over west BoB show high $\mathrm{AOD}_{500}(>0.5)$, clustering in the fine-mode growth wing $(\alpha \sim 1.2-1.4, d \alpha \sim-0.4)$ presenting large similarities with those found over urban Beijing and Kanpur (Gobbi et al., 2007). Despite the large scatter, an increase of AOD with constant $\eta(\sim 80 \%)$ leads to an increase in $\alpha$ and decrease in $R_{\mathrm{f}}$ indicating larger abundance of freshly emitted aerosols and pollutants with smaller $R_{\mathrm{f}}$. Similarly, Moorthy et al. (2010) observed the highest fine-mode fraction (0.70.8 ) over western $\mathrm{BoB}$. The north $\mathrm{BoB}$ seems to be more inhomogeneous as regards the $\alpha$ vs. $d \alpha$ plot (e.g. large variation in $d \alpha$ and $\eta$ even for the same $\alpha$ value); however $\eta$ increases with increasing of AOD and a slight decrease of $\alpha$. The extension of the north BoB pollution to higher AODs leads to larger $R_{\mathrm{f}}$ and $\eta(80-90 \%)$ as those found over urban AERONET locations (Gobbi et al., 2007; Basart et al., 2009). The observed pattern over north BoB is characteristic of coagulation of the fine-mode aerosols under turbid conditions or of mixing of pollution with mineral aerosols as the chemical analysis shown (Kumar et al., 2010). Atmospheric conditions with dominance of coarse-mode particles $(n=10-30 \%)$ are found only over south-central BoB. Over 


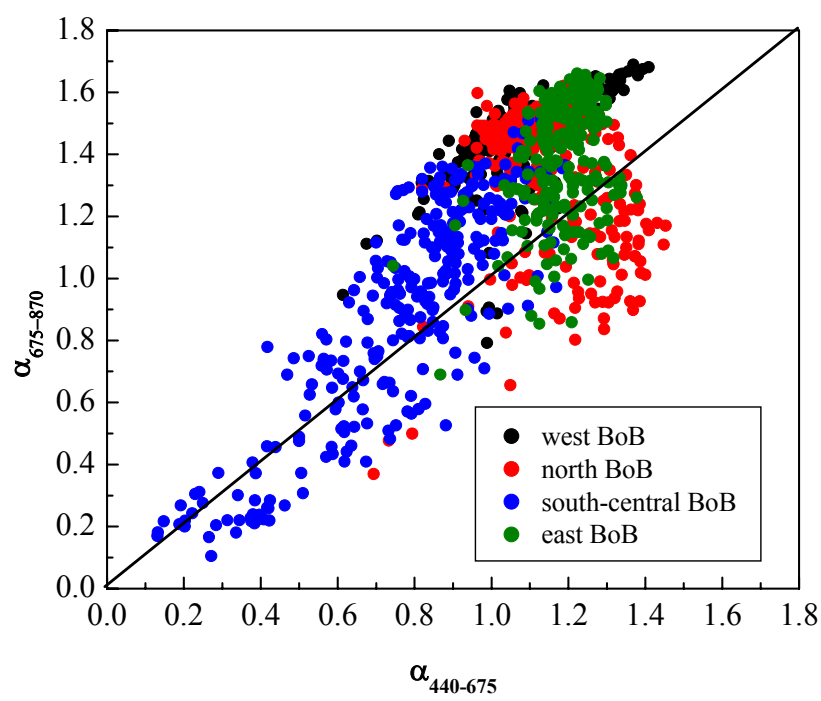

Fig. 11. Correlation between $\alpha_{440-675}$ with $\alpha_{675-870}$ over the four BoB sub-regions.

this region, there is no clear evidence for a standard particle modification process for increasing AOD. Thus, enhanced turbidity can suggest either air-pollution transport (increase in $R_{\mathrm{f}}, \eta$ and $\alpha$ ) or increase in coarse aerosols (movement of the data points towards the origin along a nearly constant $R_{\mathrm{f}} \sim 0.15 \mu \mathrm{m}$ with decreasing $\eta$ and $\alpha$ ). These two opposite directions depend on air mass movement (either from IGP in central $\mathrm{BoB}$ or from southeast Asia in south $\mathrm{BoB}$ ) transporting aerosols of different optical and chemical characteristics (Kumar et al., 2010). Over the eastern BoB, the aerosols can be, in general, divided into two groups for a threshold of $\mathrm{AOD}_{500} \sim 0.4$. Cases with lower AODs exhibit larger $\alpha$ values, also having a wide range of $\eta$ and $d \alpha$. For $\mathrm{AOD}_{500}>0.4 \alpha$ shifts towards lower values, with the vast majority of the cases having negative $a_{2}$, while the aerosol field may be composed of fine $(\eta>60 \%)$ aerosols. This indicates a coagulation aging and/or hydration of aerosols (increase in $R_{\mathrm{f}}$ ), similar to that found over locations influenced by seasonal biomass burning, e.g. Alta Floresta and Mongu (Gobbi et al., 2007). It should be noted that during the ship cruise in the eastern $\mathrm{BoB}$ the prevailing easterly winds transported biomass-burning aerosols from extensive forest fires in southeast Asia (Moorthy et al., 2010). These results justify the large AP fraction found over east BoB (Fig. 6).

The more negative $d \alpha$ with increasing AOD is an indication of fine-mode dominance under high AODs, as also observed over biomass-burning regions (Eck et al., 2001). Although being a marine environment the $\alpha$ vs. $d \alpha$ plot over BoB presents larger similarities with those found over various continental AERONET sites (Gobbi et al., 2007; Basart et al., 2009) than those observed over AS during premonsoon season (Kaskaoutis et al., 2010).
Figure 11 shows the correlations between $\alpha_{440-675}$ and $\alpha_{675-870}$ used in Figs. 9 and 10. In all the BoB sub-regions the regressions present large scatter and a pronounced curvature as evidenced by the very small fraction of total points lying on the $x=y$ line. The rare occurrence of coarse-mode aerosols under turbid conditions is the most important reason for this fact (Eck et al., 1999, 2005; Kaskaoutis et al., 2007b), while their larger fraction in south-central BoB improves significantly the correlation. In contrast, the high fine-mode fraction in west, east and parts of north BoB leads to significantly larger $\alpha_{675-870}$ values and lower correlations. Despite the overall dominance of fine-mode aerosols, the larger coarse-mode fraction over south-central BoB is mainly attributed to the combined effects of both mixing processes (mainly coagulation and humidification) and local sea-salt production. There are several indications justifying it: (i) the larger wind speed over southern $\mathrm{BoB}$ associated with higher concentration of super-micron aerosols (Sinha et al., 2011b), (ii) the aerosol-size growth via humidification in a more humid environment, (iii) the absence of significant continental influence as the region is $>400 \mathrm{~km}$ from mainland, (iv) the air-mass trajectories are mainly oceanic in nature (Raghavendra Kumar et al., 2011).

Figure 12 shows the spatial distribution of the water-vapor content (WVC) (a) and coefficient $a_{2}$ (b) over BoB during W-ICARB. In the computations of WVC the residual effect of the aerosol correction on $936 \mathrm{~nm}$ may bias the retrievals, but without causing large uncertainties in the computed results, at least for the scope of the present analysis. Large negative values of $a_{2}$ are observed along the east Indian coast and north $\mathrm{BoB}$, while somewhat lower negative values are observed over east BoB. The clear dominance of fine-mode aerosols is dictated while the coarse-mode particles (positive $a_{2}$ ) are limited over south, southwest and parts of central and northeastern BoB. On the other hand, the areas covered by negative $a_{2}$ were not so extended over AS during pre-monsoon season (Kaskaoutis et al., 2010). The WVC presents larger values over parts of south $B o B$, while in west $\mathrm{BoB}$ considerable low values are found, directly influenced by the dry continental winds. It was found (Sinha et al., 2011b) that over the regions with high WVC, RH and sea-surface wind speed were also high. The comparison of the spatial distributions between WVC and $a_{2}$ shows that the regions with large $\mathrm{WVC}$ are mainly associated with positive $a_{2}$ values suggesting size distributions dominated by coarse aerosols and are indicative of aerosol growth via humidification.

The correlations between WVC and $a_{2}$ for various $\mathrm{AOD}_{550}$ (a) and $\alpha_{380-870}$ (b) intervals are shown in Fig. 13. The importance of these correlations is to identify the modification of the fine-to-coarse mode fraction (defined via $a_{2}$ ) as a function of $\mathrm{WVC}$ for various levels of $\mathrm{AOD}_{500}$ and $\alpha_{380-870}$, The correlation shows a general increasing trend of $a_{2}$ with WVC despite the large scatter observed for $\mathrm{WVC}<2.0$. This indicates an increase of the coarse-mode 

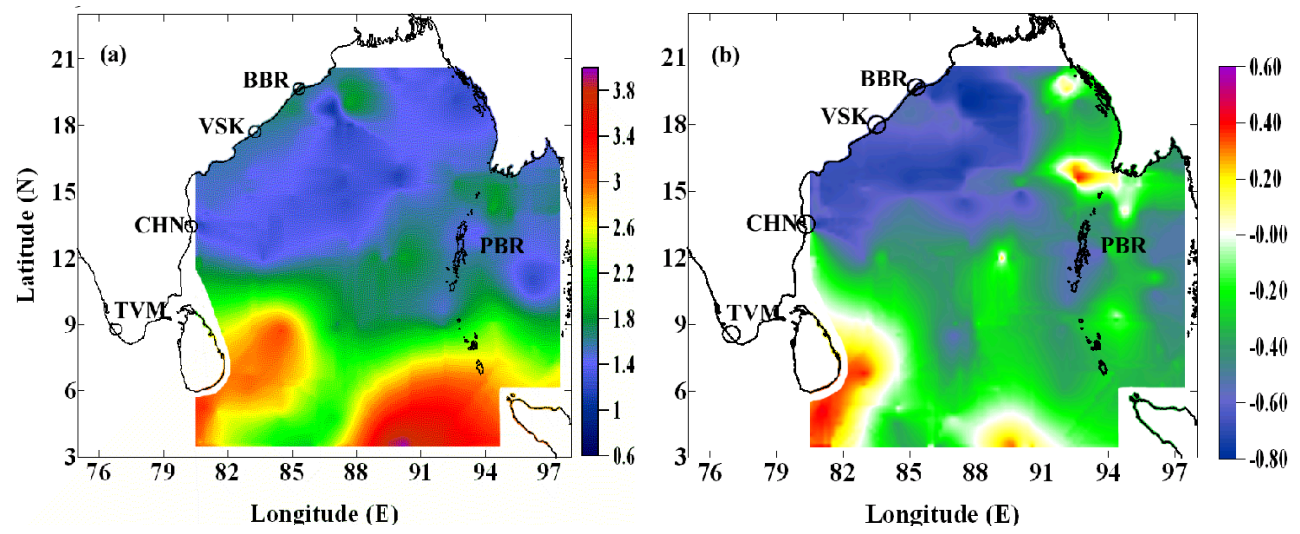

Fig. 12. Spatial distribution of WVC (a) and coefficient $a_{2}$ (b) over BoB during W-ICARB.

(a)

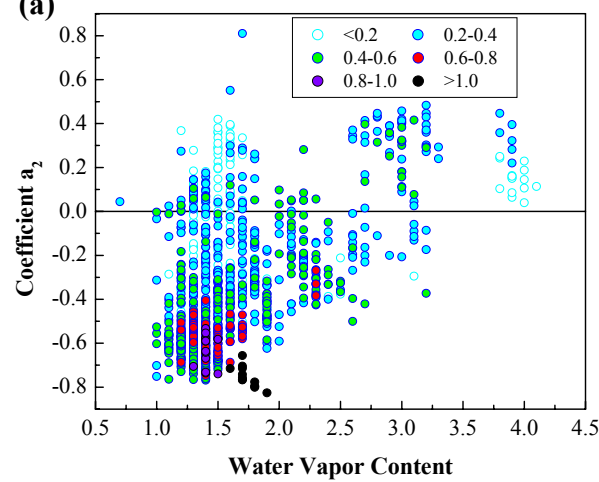

(b)

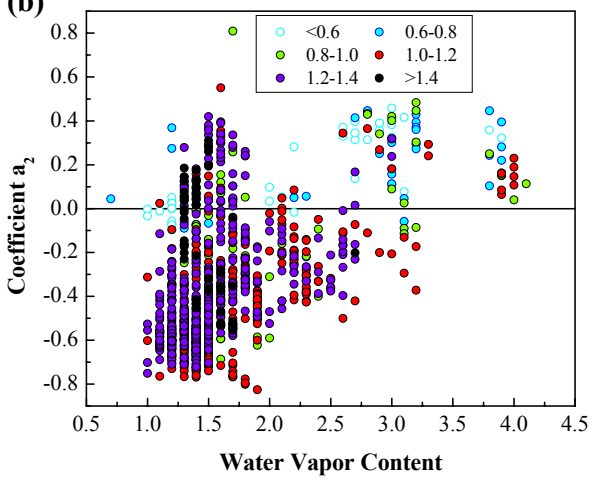

Fig. 13. Correlation between $\mathrm{WVC}$ and coefficient $a_{2}$ for various $\mathrm{AOD}_{500}$ (a) and $\alpha_{380-870}$ (b) intervals.

fraction under higher humidity levels underlying aerosol growth via humidification. The WVC vs. $a_{2}$ correlation becomes more intense for increasing $\mathrm{AOD}_{500}$ till $\sim 0.6$, meaning that the aerosol growth is more intense under turbid conditions. An increase in fine-mode particle radius (lower $\alpha$ ) with increasing WVC results in aerosol growth due to coagulation and hygroscopic swelling of the particles. This is underlined in Fig. $13 \mathrm{~b}$ where for WVC $>2.5 \mathrm{~cm}$ the $\alpha_{380-870}$ values are below 1.0 in the vast majority of the cases. On the other hand, the coarse-mode particles can be coated with pollution or biomass smoke from the forest fires in southeast Asia increasing the $\alpha_{380-870}$ values. However, these results can be considered only qualitatively and not quantitatively, since there are several parameters influencing the aerosol size distribution and the coefficient $a_{2}$, while in Figs. 12 and 13 only the humidification process is discussed. Nevertheless, the results show a considerable influence of the WVC on AOD curvature effects, especially in southern parts of BoB, which partly supporting the humidification effect discussed in Fig. 10c for south-central BoB.
The WVC and RH seem to play an important role in the aerosol particle size, especially for water-soluble anthropogenic aerosols. From extensive measurements during TARFOX it was established that the variation of $\mathrm{RH}$ was highly correlated with aerosol effective radius (Ferrare et al., 2000). Hygroscopic growth at high RH tends to increase AOD, since accumulation-mode particles increase in size favored by the presence of specific components, such as sulfate from coal combustion. It is also well known that the higher growth factor includes the hygroscopic and watersoluble particles (e.g Day and Malm, 2001). In-situ measurements of pollution aerosols over the coasts of Korea and Japan during ACE-Asia showed that the urban/anthropogenic aerosols were moderately-to-strongly hygroscopic (Carrico et al., 2003). It was found that similar features, i.e. watersoluble aerosols (see next section), dominate over Indian oceanic regions (Kumar et al., 2008, 2010; Reddy et al., 2008). The gas-to-particle conversion dominates the coastal regions of $\mathrm{BoB}$; the winds carry the precursor gases with them that get nucleated along the wind trajectory into small particles. On the other hand, seasonal changes in the aerosol size and its influence on AOD were seen over urban Indian 
Table 2. Aerosol optical parameters in the $5 \mathrm{BoB}$ sub-regions through OPAC model.

\begin{tabular}{lllllllll}
\hline BoB subregion & $\sigma_{\text {ext }}(550 \mathrm{~nm})$ & $\sigma_{\text {sca }}(550 \mathrm{~nm})$ & $\sigma_{\text {abs }}(550 \mathrm{~nm})$ & SSA $(550 \mathrm{~nm})$ & $g(550 \mathrm{~nm})$ & AOD $(500 \mathrm{~nm})$ & $\alpha_{350-500}$ & $\alpha_{500-800}$ \\
\hline West & 0.413 & 0.356 & 0.056 & 0.863 & 0.685 & 0.424 & 1.12 \\
North & 0.385 & 0.340 & 0.045 & 0.883 & 0.688 & 0.396 & 1.37 \\
Central & 0.276 & 0.258 & 0.018 & 0.934 & 0.706 & 0.285 & 0.97 \\
East & 0.360 & 0.302 & 0.058 & 0.840 & 0.683 & 0.372 & 1.35 \\
South & 0.289 & 0.275 & 0.014 & 0.950 & 0.721 & 0.293 & 0.11 \\
\hline
\end{tabular}

sites. Coarse-mode aerosols and/or growth of fine-mode water-soluble aerosols due to higher ambient RH resulted in higher AODs during summer, while during winter the AODs are found to be lower mostly dominated by fine-mode aerosols (Ramachandran, 2007). Thus, the detailed aerosol monitoring over $\mathrm{BoB}$ from a combination of ship-borne, airborne and satellite measurements on annual basis can improve our knowledge about aerosol properties, modification processes and climate implications.

\subsection{OPAC simulations}

In the earlier analysis some basic aerosol types were discriminated over the BoB sub-regions based on the well-known technique of correlating AOD and $\alpha$, and also using the curvature $a_{2}$ for more creditable results. However, a specific aerosol type is rather difficult to exist in the atmosphere due to strong mixing processes; thus, the mixing of different types is the common scenario. In order to obtain an "appropriate" aerosol mixture able to represent the prevailing atmospheric conditions over BoB, standard aerosol models outlined in Optical Properties of Aerosols and Clouds (OPAC) (Hess et al., 1998) have been used. The OPAC model provides the optical properties of various aerosol types and new mixtures can be defined from the given aerosol components to simulate the aerosol properties that are used for the calculation of aerosol radiative forcing (ARF) (e.g. Ramachandran and Kedia, 2010; Pathak et al., 2010). The number density of each component is adjusted maintaining the measured parameters intact with the observations (e.g. Satheesh et al., 2010), while the measured BC concentrations were used for the definition of the soot component. Although OPAC is widely used by the scientific community, the standard aerosol models used have some inconsistencies, especially for the $\mathrm{BC}$ refractive index. Thus, the division in to aerosol components may be slightly different if different optical properties were used. Various aerosol models were varied iteratively until satisfactory agreement $(\sim 5 \%)$ was achieved between modeled and measured spectral AODs. This technique was applied in the distinct BoB sub-regions, while the southcentral region has been divided into two. The measured and modeled spectral AODs over the five BoB sub-regions are shown in Fig. 14. OPAC was used for $70 \% \mathrm{RH}$, which is the closest value in all regions, while mean regional spectral AODs have been used in the calculations. The measured and
Table 3. Percentage $\%$ contribution of each aerosol component in the $5 \mathrm{BoB}$ sub-regions according to OPAC model. The mean and standard deviations are also given. [waso: water soluble, ssam: seasalt accumulation mode, sscm: sea-salt coarse mode, mitr: mineral transported].

\begin{tabular}{llllllll}
\hline & West & North & Central & East & South & Mean & Stdev \\
\hline soot & 6.77 & 5.51 & 2.23 & 8.06 & 1.27 & 4.77 & 2.92 \\
waso & 71.32 & 70.46 & 51.14 & 67.14 & 35.44 & 59.10 & 15.54 \\
ssam & 20.89 & 23.90 & 45.54 & 23.84 & 43.33 & 31.51 & 11.89 \\
sscm & 0.23 & 0.07 & 1.06 & 0.89 & 19.95 & 4.44 & 8.69 \\
mitr & 0.78 & 0.06 & 0.04 & 0.07 & 0.01 & 0.19 & 0.33 \\
\hline
\end{tabular}

simulated $\alpha$ values are also given, while all regions show a consistency between measured and simulated AODs. However, it should be noted that the observed OPAC simulations may not be the most perfect, the results obtained provide $5 \%$ uncertainty with the measured spectral AODs. The root mean square (RMS) differences between the measured and simulated $\mathrm{AOD}_{500}$ were found to be $0.021,0.01,0.004,0.012$ and 0.014 for west, north, central, east and south BoB, respectively. Based on this consistency an aerosol model has been developed for each BoB sub-region capable of reproducing the measured spectral AOD. The optical properties of each aerosol model over the five BoB sub-regions are given in Table 2. The extinction $\left(\sigma_{\text {ext }}\right)$ and scattering $\left(\sigma_{\text {sca }}\right)$ coefficients are larger over west and north $\mathrm{BoB}$, while larger values of absorption coefficient $\left(\sigma_{\mathrm{abs}}\right)$ are observed over east $\mathrm{BoB}$. South and central $\mathrm{BoB}$ are found to be more transparent regions with the lowest AOD, $\sigma_{\text {ext }}, \sigma_{\text {sca }}$ and $\sigma_{\mathrm{abs}}$, also having the largest SSA and $g$ values indicative of aerosols of scattering nature. In contrast, west, north and especially the eastern part of $\mathrm{BoB}$ are found to be dominated by aerosols having a significant absorbing capability $(\mathrm{SSA}<0.88)$. These results are in line with those reported by Raghavendra $\mathrm{Ku}-$ mar et al. (2011) used for ARF retrievals. More specifically, they computed mean values of SSA and $g$ over entire BoB of $0.88 \pm 0.05$ and $0.71 \pm 0.03$, respectively, which are in excellent agreement with our results $(0.89 \pm 0.05$ and $0.70 \pm 0.02$, respectively).

These aerosol properties correspond to a mixture composed of various standard models included in OPAC. The $\%$ contribution (volume mixing ratio $\times 100$ ) for each of 

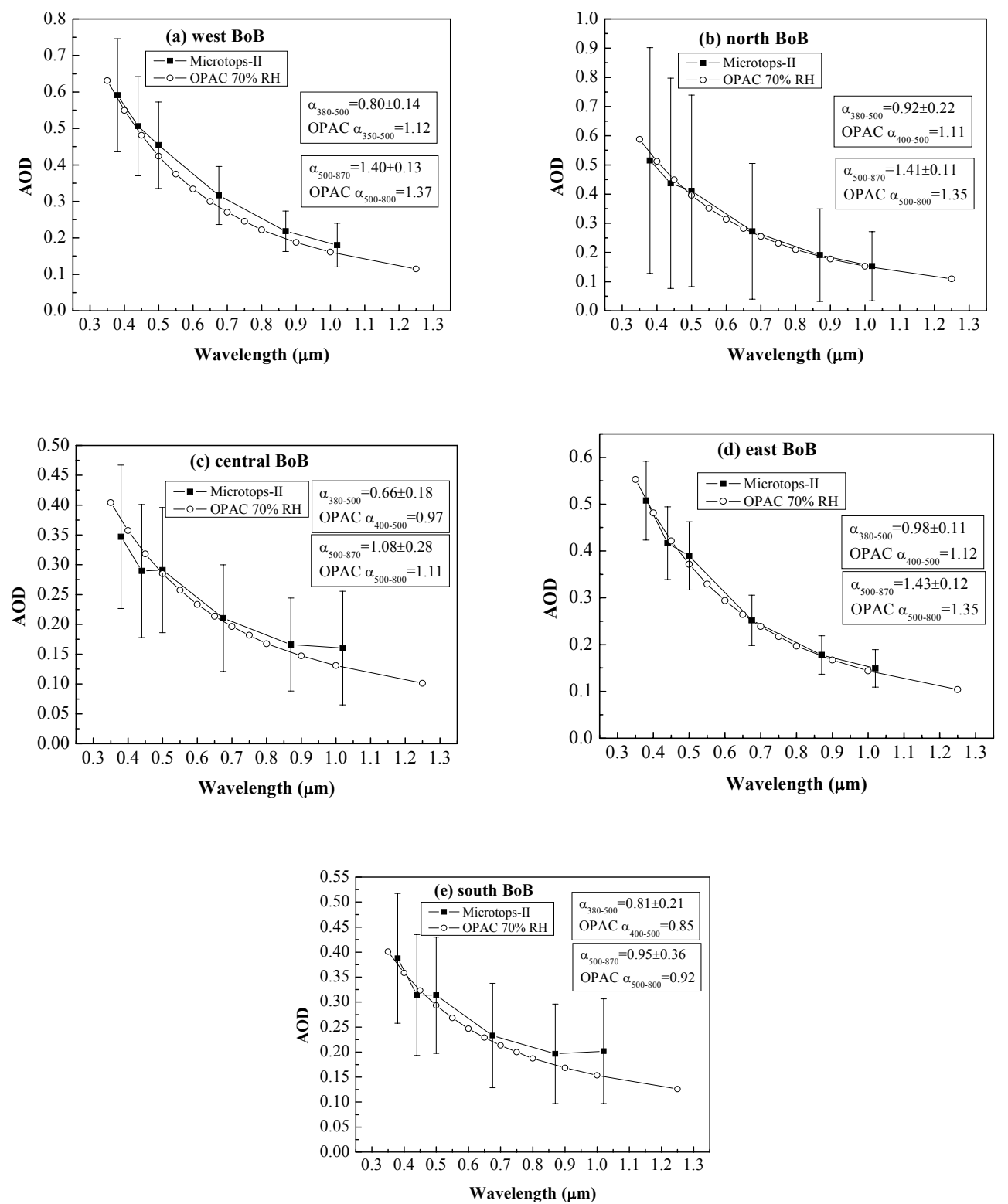

Fig. 14. Measured and OPAC-simulated (at $70 \% \mathrm{RH}$ ) spectral AOD over $5 \mathrm{BoB}$ sub-regions. The vertical bars express one standard deviation from the regional mean AOD value.

the 5 standard aerosol models is shown in Table 3. The water-soluble aerosol component originates from gas-toparticle conversion and mainly consists of various kinds of sulfates, nitrates and organic particles; this type dominates in the BoB sub-regions with fractions between $35 \%$ and $70 \%$. However, over the southern part of BoB the seasalt accumulation mode dominates, since this region is far from continents and open to the tropical Indian Ocean. The soot contribution varies from $\sim 1.2 \%$ (south $\mathrm{BoB}$ ) to $\sim 8 \%$ (east $\mathrm{BoB}$ ), with the latter being a very large value for marine environments. Since the soot contribution was found to be $\sim 5-12 \%$ over continental India (e.g. Ramachandran and Rajesh, 2007; Pathak et al., 2010; Satheesh et al., 2010) its large fractions over west, north and east BoB highlight the strong anthropogenic influence and the outflow of pollutants over the marine environment during winter. It may also be noted that $\mathrm{BC}$ concentrations are larger during winter season throughout the Indian sub-continent (Badarinath et al., 2009b). An interesting feature that is revealed from Table 3 is the nearly absence of mineral-transported aerosols corresponding to dust particles; however, they exhibit larger fraction over west BoB justified from the chemical analysis of the IGP outflow (Kumar et al., 2010). The coarsemode sea-salt aerosol is found over the southern part of 

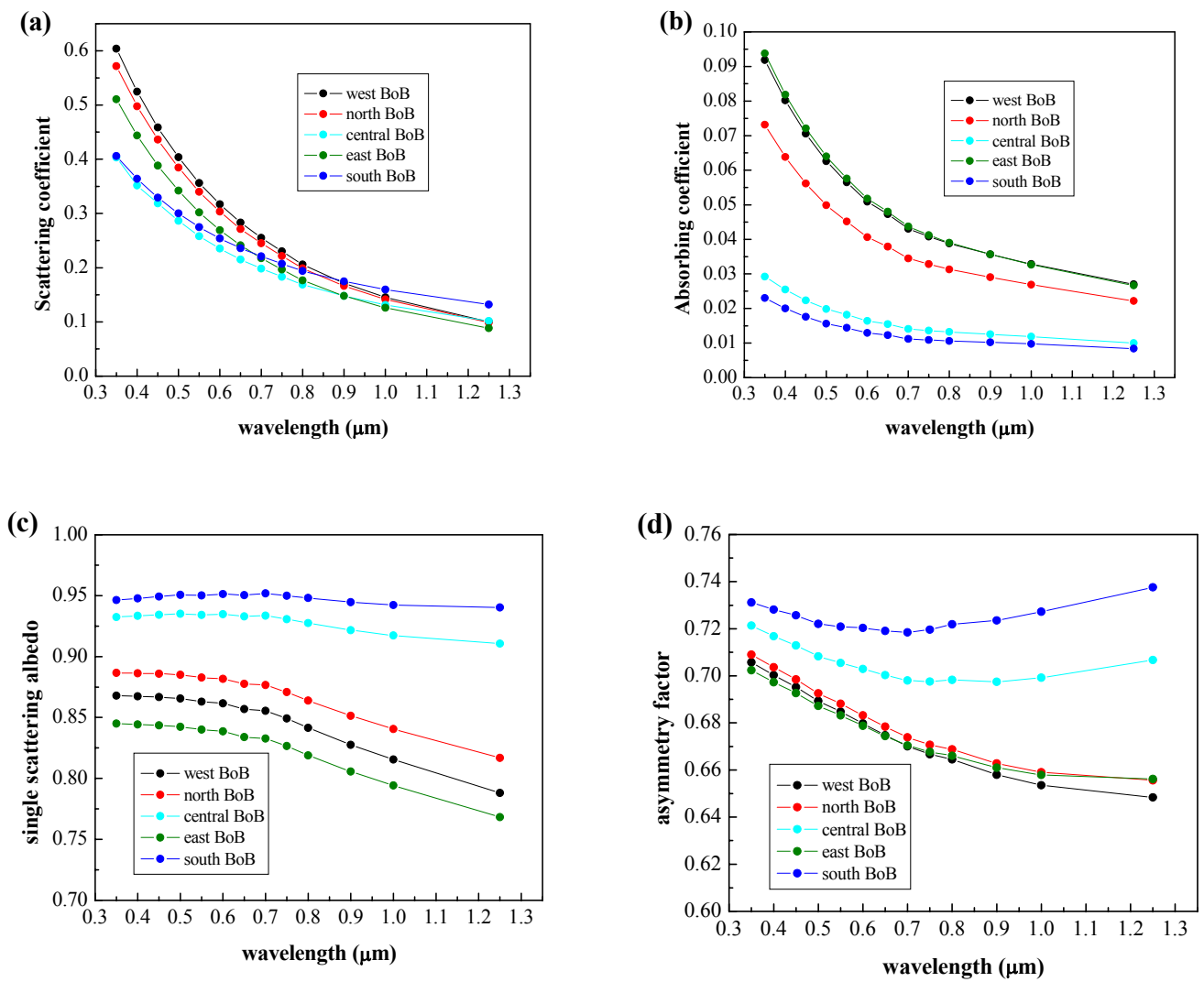

Fig. 15. Spectral variation of the scattering coefficient (a), absorption coefficient (b), single scattering albedo (c) and asymmetry factor (d) over the 5 BoB sub-regions obtained via OPAC simulations.

BoB (20\%) due to the stronger winds (Sinha et al., 2011b). Our results are verified by Sarin et al. (2011) during the same cruise campaign. They found that the mean contribution of water-soluble components (nss- $\mathrm{SO}_{4}^{-2}, \mathrm{NO}^{-3}, \mathrm{NH}^{+4}$ ) and soot in the $\mathrm{PM}_{10}$ was $58 \%$ and $4 \%$, respectively, which is in excellent agreement with our results $(59.1 \pm 15.54 \%$ and $4.77 \pm 2.92 \%$, respectively).

Figure 15 presents the spectral variation of $\sigma_{\mathrm{sca}}(\mathrm{a}), \sigma_{\mathrm{abs}}$ (b), SSA (c) and g (d) for each BoB sub-region. The spectral variation of $\sigma_{\text {sca }}$ shows similar values for all regions at longer wavelengths, while as the wavelength decreases $\sigma_{\text {sca }}$ shows higher values over the northern and western parts of BoB due to combined effects of larger AOD and $\alpha$, which enhances scatter at the shorter wavelengths (Schuster et al., 2006). On the other hand, the larger presence of coarse-mode aerosols over the southern $\mathrm{BoB}$ is responsible for the larger AODs for wavelengths above $\sim 900 \mathrm{~nm}$. Opposite to $\sigma_{\text {sca }}$, the spectral variation of $\sigma_{\text {abs }}$ clearly differentiates the absorbing capability of the aerosols over the distinct areas. Thus, in the eastern and western parts of $\mathrm{BoB}$, the aerosols are found to be more absorbing, while in the southern and central regions low absorbing nature is seen. Large and low $\sigma_{\mathrm{abs}}$ values were also found over north-western and southern BoB, respectively during ICARB (Moorthy et al., 2009), while the strong absorbing aerosols over the eastern BoB are observed for the first time. Similarly to $\sigma_{\mathrm{abs}}$, the SSA spectral variation shows presence of absorbing and non-absorbing areas in BoB; the eastern part is the most absorbing, which is directly influenced by biomass-burning aerosols from south-east Asia. Note also the decreasing SSA values with wavelength over western, northern and eastern BoB indicating aerosols of anthropogenic and/or biomass-burning origin, while the larger SSA values over central and southern BoB present neutral wavelength dependence, characteristic of aerosols of marine origin (Dubovik et al., 2002). Similarly to SSA, the spectral variation of $g$ shows classification of the aerosols into fine and coarse modes, indicating more isotropic scattering (lower $g$ values, decrease with wavelength) for the finemode aerosols and preference of forward scattering (larger $g$ values, increase at longer wavelengths) for coarse-mode aerosols (Dubovik et al., 2002) over the central and southern BoB.

The wavelength dependence of the absorption coefficient is further examined over the $\mathrm{BoB}$ sub-regions with a view of determining the role of $\mathrm{BC}$ in light absorption. Absorbing aerosols produced by different sources, i.e. biomass burning or urban emissions can be distinguished by different wavelength dependence in light absorption with the former having 


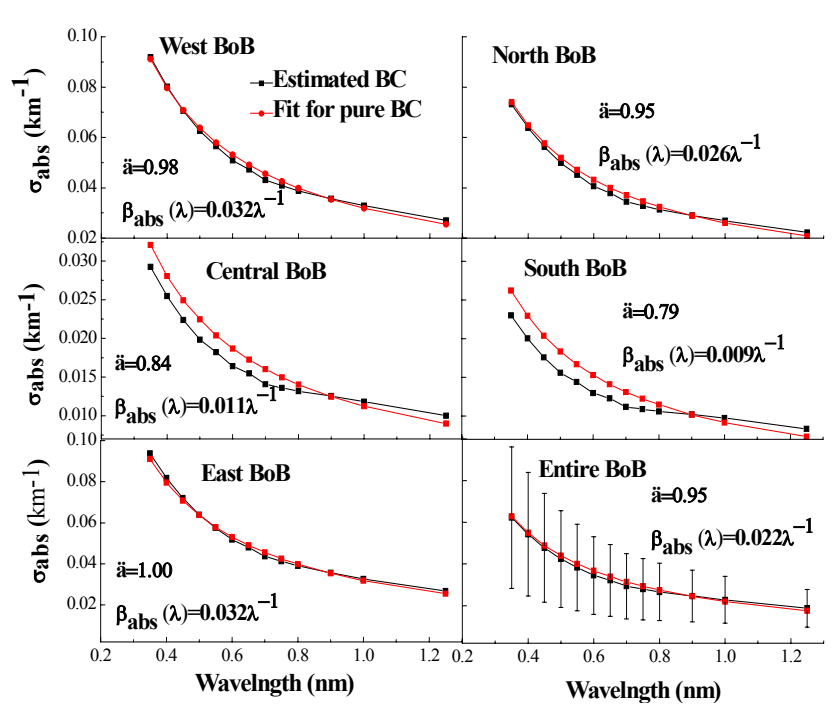

Fig. 16. Wavelength dependence of the absorption coefficient for estimated BC (OPAC) and that for pure BC assuming an absorption wavelength exponent $\mathrm{a}=1$.

much stronger wavelength dependence (Kirchstetter et al., 2004 and references therein). Figure 16 shows the wavelength dependence of the absorption coefficient for estimated $\mathrm{BC}$ and that for pure $\mathrm{BC}$ rendering the absorption wavelength exponent $\ddot{a}=1$. The dependence of the aerosol absorption on wavelength was parameterized using a power-law relationship: $\sigma_{\mathrm{abs}}=\mathrm{K} \lambda^{-\ddot{\mathrm{a}}}$, where $\mathrm{K}$ is a constant and $\ddot{\mathrm{a}}$ the absorption Ångström exponent. Initially, we made a scatter plot using the estimated absorption coefficient from OPAC and found the value of intercept $\mathrm{K}$, which is sensitive to the magnitude of the aerosol absorption in different regions. We have computed the $\mathrm{BC}$ absorption coefficient $\left(\mathrm{b}_{\mathrm{abs}}\right)$ by assuming that $\ddot{\mathrm{a}}=1$ for pure $\mathrm{BC}$ contribution. Thus, the divergence from a $\lambda^{-1}$ spectral dependency indicates the presence of aerosol species other than BC that absorb in the UV and visible spectral regions (Kirchstetter et al., 2004).

The aerosol light absorption is found to be larger in the western, eastern and northern parts of $\mathrm{BoB}$, while it is significantly reduced in the central and southern parts. The larger $\ddot{a}$ in the eastern $\mathrm{BoB}$ is found to be due to enhanced light absorption for $\lambda<\sim 0.6 \mu \mathrm{m}$. In this region, note also the slightly higher curve of estimated BC for $\lambda<0.4 \mu \mathrm{m}$ suggesting a stronger wavelength dependence compared to that of pure BC. This probably indicates a contribution of organic carbon (OC) aerosols from the frequent forest fires in southeast Asia having stronger light absorption wavelength dependence than that for pure BC, as also observed in south Africa during SAFARI campaign (Kirchstetter et al., 2004); the absorption efficiency of BC is larger but with weaker wavelength dependence. Thus, ä values lower than 1 indicate nearly absence of acetone soluble OC over BoB, especially in the central and southern parts. In western BoB the soot component was found to be large ( $\sim 7 \%)$; the ä value is 0.98 indicating nearly exclusive $\mathrm{BC}$ contribution to light absorption. Eastern coastal India is highly urbanized and industrialized and controls the aerosol field in coastal BoB (e.g. Satheesh et al., 2009), while the coal-combustion emissions dominate during winter (Venkataraman et al., 2005; Prasad et al., 2006). The aerosols of such emissions were found to have strong absorption wavelength dependence (Bond, 2001; Bond et al., 1999). Similar wavelength dependence (ä $\sim 1$ ) was found for soot and urban aerosols (Rosen et al., 1978; Bergstrom et al., 2002; Horvath et al., 1997). The slight lower ä values in the northern parts of BoB may be attributed to hazy atmospheric conditions often occurred in IGP during winter season (e.g. Singh et al., 2004) affecting northern head of BoB under favorable wind conditions. Similarly, the ä values were larger (average of 1.9) in savanna biomassburning samples during SAFARI 2000 than those (average of 1.2) found with the presence of hazy samples aloft (Kirchstetter et al., 2004). In contrast, over central and south BoB the absorption of light is much lower, also exhibiting weak wavelength dependence. This indicates that the BC contribution to absorption is much lesser, while other species having lower absorption efficiency play a dominant role. The ä values in these areas are comparable to those found (0.8-0.9) for motor-vehicle samples (urban aerosols) in Berkeley, USA (Kirchstetter et al., 2004). The whole analysis of the absorbing aerosols over BoB and the results obtained are strongly verified by the chemical analysis (Kumar et al., 2010) discussed in the previous sections.

\section{Conclusions}

This study focused on the classification of aerosols over the entire BoB during W-ICARB cruise campaign (27 December 2008 to 30 January 2009) using ship-borne measurements of spectral AOD. The results showed a large spatio-temporal variation of the examined aerosol properties (e.g. AOD 500 , $\alpha_{380-870}$, and $a_{2}$ ) over BoB strongly affected by the continents, the outflow of pollutants, the meteorological parameters (wind speed and direction, $\mathrm{RH}$ ) and the mixing processes (e.g. coagulation, humidification) in the marine atmosphere. The highest $\mathrm{AOD}_{500}$ was observed in western and northern BoB with lower values in the southern and parts of central BoB. The eastern BoB, which was investigated for the first time, presented concurrently high values of both $\mathrm{AOD}_{500}$ $(0.39 \pm 0.07)$ and $\alpha_{380-870}(1.27 \pm 0.09)$. Large $\alpha_{380-870}$ values were also observed in the western and northern parts of BoB closely associated with high AODs indicating a large fraction of anthropogenic aerosols and/or biomass burning during winter season. This was also justified by the curvature ( $a_{2}$ values) being negative in the vast majority of the cases highlighting large fraction of fine-mode aerosols. A larger fraction of coarse-mode particles (positive $a_{2}$ values) was found over the central-south parts of BoB far away from 
the coast. Over these regions both wind speed and WVC have larger values, which may play an important role in aerosol growth via humidification or sea-salt production.

The classification of the aerosols was achieved by means of the widely used method that relates parameters corresponding to aerosol load $\left(\mathrm{AOD}_{500}\right)$ and particle size $\left(\alpha_{380-870}\right)$. This correlation showed that the main aerosol type over $\mathrm{BoB}$ corresponded to the $\left(\mathrm{AOD}_{500}, \alpha_{380-870}\right)$ pair of $(\sim 0.4,1.2)$, which is similar to that found over urban Hyderabad during winter season. The classification scheme indicated an extremely large fraction of fine-mode aerosols in turbid atmospheres, which is even larger than $90 \%$ in the western part of $\mathrm{BoB}$ and approaches $100 \%$ over eastern $\mathrm{BoB}$. This was the most exciting finding in the present work, which differentiates the aerosol characteristics over BoB during winter and pre-monsoon seasons. The clean maritime conditions were nearly absent, while quite interesting was the low fraction of mixed aerosols, which was dominant over $\mathrm{BoB}$ and AS during pre-monsoon season.

Given the high spatial and temporal variability of atmospheric aerosols over $\mathrm{BoB}$, unique aerosol types are difficult to occur; in contrast, aerosols with internal and external mixtures of various components (natural and anthropogenic) were presented. Such mixtures, along with complex aerosol properties, have been simulated via OPAC model, revealing a significant (6-8\%) soot component in north-western and eastern $\mathrm{BoB}$, while the coarse-mode sea-salt aerosols were limited over the southern parts of $\mathrm{BoB}$. The aerosols over northwestern and eastern $\mathrm{BoB}$ were of absorbing nature having low SSA values; for these samples the BC was found to be the dominant light-absorbing aerosol component. These results introduce significant heating of the lower atmosphere able to influence the local monsoon system. In the following years we might expect aerosol concentrations to increase in respect to the rapid economic development that is taking place in India. Therefore, it needs continuous and systematic efforts to monitor the aerosol field and properties over this region since the knowledge of their effects on the marine environment and in our changing planet is a real challenge.

Acknowledgements. The authors are thankful to Director, NRSC and Dy. Director (RS\&GIS-AA) for necessary help at various stages and ISRO-GBP via W-ICARB project for funding support. We also thank the Department of Ocean Development for giving the opportunity to conduct measurements on board Sagar Kanya.

Edited by: E. Highwood

\section{References}

Badarinath, K. V. S., Kharol, S. K., Sharma, A. R., and Roy, P. S.: Fog over Indo-Gangetic Plains - a study using multi-satellite data and ground observations, IEEE J. Sel. Top. Appl., 2, 185195, 2009a.

Badarinath, K. V. S., Kharol, S. K., Reddy, R. R., Rama Gopal, K., Narasimhulu, K., Siva Sankara Reddy, L., and Raghavendra Kumar, K.: Black carbon aerosol mass concentration variation in urban and rural environments of India - a case study, Atmos. Sci. Lett., 10, 29-33, 2009b.

Basart, S., Pérez, C., Cuevas, E., Baldasano, J. M., and Gobbi, G. P.: Aerosol characterization in Northern Africa, Northeastern Atlantic, Mediterranean Basin and Middle East from direct sun AERONET observations, Atmos. Chem. Phys., 9, 8265-8282, doi:10.5194/acp-9-8265-2009, 2009.

Bergstrom, R. W., Russell, P. B., and Hignett, P.: Wavelength dependence of the absorption of black carbon particles: predictions and results from the TARFOX experiment and implications for the aerosol single scattering albedo, J. Atmos. Sci., 59, 567-577, 2002.

Bond, T. C.: Spectral dependence of visible light absorption by carbonaceous particles emitted from coal combustion, Geophys. Res. Lett., 28, 4075-4078, 2001.

Bond, T. C., Bussner, M., Wehner, B., Keller, S., Charlson, R. J., and Heintzenberg, J.: Light absorption by primary particle emissions from a lignite burning plant, Environ. Sci. Technol., 33, 3887-3891, 1999.

Cachorro, V. E., Romero, P. M., Toledano, C., Cuevas, E., and de Frutos, A. M.: The fictitious diurnal cycle of aerosol optical depth: a new approach for "in situ" calibration and correction 5 of AOD data series, Geophys. Res. Lett., 31, L12106, doi:10.1029/2004GL019651, 2004.

Carmona, I. and Alpert, P.: Synoptic classification of MODIS aerosols over Israel, J. Geophys. Res., 114, D07208, doi:10.1029/2008JD010160, 2009.

Carrico, C. M., Kus, P., Rood, M. J., Quinn, P. K., and Bates, T. S.: Mixtures of pollution, dust, sea salt, and volcanic aerosol during ACE-Asia: radiative properties as a function of relative humidity, J. Geophys. Res., 108(D23), 8650, doi:101029/2003JD003405, 2003.

Chin, M., Diehl, T., Dubovik, O., Eck, T. F., Holben, B. N., Sinyuk, A., and Streets, D. G.: Light absorption by pollution, dust, and biomass burning aerosols: a global model study and evaluation with AERONET measurements, Ann. Geophys., 27, 3439-3464, doi:10.5194/angeo-27-3439-2009, 2009.

Das, S. K., Jayaraman, A., and Misra, A.: Fog-induced variations in aerosol optical and physical properties over the Indo-Gangetic Basin and impact to aerosol radiative forcing, Ann. Geophys., 26, 1345-1354, doi:10.5194/angeo-26-1345-2008, 2008.

Day, D. E. and Malm, W. C.: Aerosol light scattering measurements as a function of relative humidity: a comparison between measurements made at three different sites, Atmos. Environ., 35 , 5169-5176, 2001.

Dey, S. and Singh, R. P.: Retrieval of aerosol parameters using IRS P4 OCM data over the Arabian Sea and the Bay of Bengal, Curr Sci. India, 83, 1235-1240, 2002.

Dey, S. and di Girolamo, L.: A climatology of aerosol optical and microphysical properties over the Indian subcontinent from 9 years (2000-2008) of Multiangle Imaging Spec- 
troradiometer (MISR) data, J. Geophys. Res., 115, D15204, doi:10.1029/2009JD013395, 2010.

Dubovik, O., Holben, B. N., Eck, T. F., Smirnov, A., Kaufman, Y. J., King, M. D., Tanrè, D., and Slutsker, I.: Variability of absorption and optical properties of key aerosol types observed in worldwide locations, J. Atmos. Sci., 59, 590-608, 2002.

Eck, T. F., Holben, B. N., Reid, J. S., Dubovik, O., Smirnov, A., O'Neill, N. T., Slutsker, I., and Kinne, S.: Wavelength dependence of the optical depth of biomass burning, urban, and desert dust aerosols, J. Geophys. Res., 104(D24), 31333-31349, 1999.

Eck, T. F., Holben, B. N., Dubovik, O., Smirnov, A., Slutsker, I., Lobert, J. M., and Ramanathan, V.: Column-integrated aerosol optical properties over the Maldives during the northeast monsoon for 1998-2000, J. Geophys. Res., 106, 28555-28566, 2001.

Eck, T. F., Holben, B. N., Dubovic, O., Smirnov, A., Goloub, P., Chen, H. B., Chatenet, B., Gomes, L., Zhang, X. Y., Tsay, S. C., Ji, Q., Giles, D., and Slutsker, I.: Columnar aerosol optical properties at AERONET sites in Central Eastern Asia and aerosol transport to the Tropical Mid-Pacific, J. Geophys. Res., 110, D06202, doi:10.1029/2004JD005274, 2005.

El-Metwally, M., Alfaro, S. C., Abdel Wahab, M., and Chatenet, B.: Aerosol characteristics over urban Cairo: seasonal variations as retrieved from Sun photometer, J. Geophys. Res., 113, D14219, doi:10.1029/2008JD009834, 2008.

Ferrare, R., Ismail, S., Browell, E., Brackett, V., Clayton, M., Kooi, S., Melfi, S. H., Whiteman, D., Schwemmer, G., Evans, K., Russell, P., Livingston, J., Schmid, B., Holben, B., Remer, L., Smirnov, A., and Hobbs, P. V.: Comparison of aerosol optical properties and water vapor among ground and airborne lidars and sun photometers during TARFOX, J. Geophys. Res., 105, 99179933, 2000.

Ganguly, D., Jayaraman, A., and Gadhavi, H.: In situ ship cruise measurements of mass concentration and size distribution of aerosols over Bay of Bengal and their radiative impacts, J. Geophys. Res., 110, D06205, doi:10.1029/2004JD005325, 2005.

Ganguly, D., Jayaraman, A., Rajesh, T. A., and Gadhavi, H.: Wintertime aerosol properties during foggy and nonfoggy days over urban center Delhi and their implications for shortwave radiative forcing, J. Geophys. Res., 111, D15217, doi:10.1029/2005JD007029, 2006.

Gautam, R., Hsu, N. C., Lau, K.-M., and Kafatos, M.: Aerosol and rainfall variability over the Indian monsoon region: distributions, trends and coupling, Ann. Geophys., 27, 3691-3703, doi:10.5194/angeo-27-3691-2009, 2009a.

Gautam, R., Liu, Z., Singh, R. P., and Hsu, N. C.: Two contrasting dust-dominant periods over India observed from MODIS and CALIPSO data, Geophys. Res. Lett., 36, L06813, doi:10.1029/2008GL036967, 2009b.

Gautam, R., Hsu, C. N., and Lau, K.-M.: Premonsoon aerosol characterization and radiative effects over the Indo-Gangetic Plains: implications for regional climate warming, J. Geophys. Res., 115, D17208, doi:10.1029/2010JD013819, 2010.

Gerasopoulos, E., Amiridis, V., Kazadzis, S., Kokkalis, P., Eleftheratos, K., Andreae, M. O., Andreae, T. W., El-Askary, H., and Zerefos, C. S.: Three-year ground based measurements of aerosol optical depth over the Eastern Mediterranean: the urban environment of Athens. Atmos. Chem. Phys., 11, 2145-2159, doi:10.5194/acp-11-2145-2011, 2011

George, S. K. and Nair, P. R.: Aerosol mass loading over the marine environment of Arabian Sea during ICARB: sea-salt and nonsea-salt components, J. Earth Syst. Sci., 117, 333-344, 2008.

Gobbi, G. P., Kaufman, Y. J., Koren, I., and Eck, T. F.: Classification of aerosol properties derived from AERONET direct sun data, Atmos. Chem. Phys., 7, 453-458, doi:10.5194/acp-7-453-2007, 2007.

Hess, A. M., Koepke, P., and Schult, I.: Optical properties of aerosol and clouds: the software package OPAC, B. Am. Meteorol. Soc., 79, 831-844, 1998.

Horvath, H., Catalan, L., and Trier, A.: A study of the aerosol of Santiago de Chile III: light absorption measurements, Atmos. Environ., 31, 3737-3744, 1997.

Ichoku, C., Levy, R., Kaufman, Y. J., Remer, L. A., Li, R. R., Martins, V. J., Holben, B. N., Abuhassan, N., Slutsker, I., Eck, T. F., and Pietras, C.: Analysis of the performance characteristics of the five-channel Microtops II Sun photometer for measuring aerosol optical thickness and precipitable water vapor, J. Geophys. Res., 107(D13), 4179, doi:10.1029/2001JD001302, 2002.

Kalapureddy, M. C. R. and Devara, P. C. S.: Characterization of pre-monsoon aerosols over oceanic regions around India, Atmos. Environ., 42(28), 6816-6827, 2008.

Kalapureddy, M. C. R. and Devara, P. C. S.: Pre-monsoon aerosol optical properties and spatial distribution over the Arabian Sea during 2006, Atmos. Res., 95, 186-196, 2010.

Kalapureddy, M. C. R., Kaskaoutis, D. G., Ernest Raj, P., Devara, P. C. S., Kambezidis, H. D., Kosmopoulos, P. G., and Nastos, P. T.: Identification of aerosol type over the Arabian Sea in the premonsoon season during the ICARB campaign, J. Geophys. Res., 114, D17203, doi:10.1029/2009JD011826, 2009.

Kaskaoutis, D. G. and Kambezidis, H. D.: Investigation on the wavelength dependence of the aerosol optical depth in the Athens area, Q. J. Roy. Meteorol. Soc., 132, 2217-2234, 2006.

Kaskaoutis, D. G. and Kambezidis, H. D.: Comparison of the Ångström parameters retrieval in different spectral ranges with the use of different techniques, Meteorol. Atmos. Phys., 99, 233246, 2008.

Kaskaoutis, D. G., Kambezidis, H. D., Hatzianastassiou, N., Kosmopoulos, P. G., and Badarinath, K. V. S.: Aerosol climatology: on the discrimination of aerosol types over four AERONET sites, Atmos. Chem. Phys. Discuss., 7, 6357-6411, doi:10.5194/acpd7-6357-2007, 2007a.

Kaskaoutis, D. G., Kambezidis, H. D., Hatzianastassiou, N., Kosmopoulos, P. G., and Badarinath, K. V. S.: Aerosol climatology: dependence of the Angstrom exponent on wavelength over four AERONET sites, Atmos. Chem. Phys. Discuss., 7, 7347-7397, doi:10.5194/acpd-7-7347-2007, 2007b.

Kaskaoutis, D. G., Badarinath, K. V. S., Kharol, S. K., Sharma, A. R., and Kambezidis, H. D.: Variations in the aerosol optical properties and types over the tropical urban site of Hyderabad, India, J. Geophys. Res., 114, D22204, doi:10.1029/2009JD012423, 2009.

Kaskaoutis, D. G., Kalapureddy, M. C. R., Krishna Moorthy, K., Devara, P. C. S., Nastos, P. T., Kosmopoulos, P. G., and Kambezidis, H. D.: Heterogeneity in pre-monsoon aerosol types over the Arabian Sea deduced from ship-borne measurements of spectral AODs, Atmos. Chem. Phys., 10, 4893-4908, doi:10.5194/acp-10-4893-2010, 2010.

Kedia, S. and Ramachandran, S.: Latitudinal and longitudinal variation in aerosol characteristics from sun photometer and MODIS 
over the Bay of Bengal and Arabian Sea during ICARB, J. Earth Syst. Sci., 117(S1), 375-387, 2008.

Kedia, S. and Ramachandran S.: Variability in aerosol optical and physical characteristics over the Bay of Bengal and the Arabian Sea deduced from Angstrom exponents, J. Geophys. Res., 114, D14207, doi:10.1029/2009JD011950, 2009.

Kirchstetter, T. W., Novakov, T., and Hobbs, P. V.: Evidence that the spectral dependence of light absorption by aerosols is affected by organic carbon, J. Geophys. Res., 109, D21208, doi:10.1029/2004JD004999, 2004.

Koch, D. and Del Genio, A. D.: Black carbon semi-direct effects on cloud cover: review and synthesis, Atmos. Chem. Phys., 10, 7685-7696, doi:10.5194/acp-10-7685-2010, 2010.

Kumar, A., Sarin, M. M., and Sudheer, A. K.: Mineral and anthropogenic aerosols in Arabian Sea-atmosphere boundary layer: sources and spatial variability, Atmos. Environ., 42, 5169-5181, 2008.

Kumar, A., Sarin, M. M., and Srinivas, B.: Aerosol iron solubility over Bay of Bengal: role of anthropogenic sources and chemical processing, Mar. Chem., 121, 167-175, 2010.

Lau, K. M., Kim, M. K., and Kim, K. M.: Asian monsoon anomalies induced by aerosol direct effects, Clim. Dynam., 26, 855864, 2006.

Lawrence, M. G. and Lelieveld, J.: Atmospheric pollutant outflow from Southern Asia: a review, Atmos. Chem. Phys., 10, 11017 11096, doi:10.5194/acp-10-11017-2010, 2010.

Madhavan, B. L., Niranjan, K., Sreekanth, V., Sarin, M. M., and Sudheer, A. K.: Aerosol characterization during the summer monsoon period over a tropical coastal Indian station, Visakhapatnam, J. Geophys. Res., 113, D21208, doi:10.1029/2008JD010272, 2008.

Menon, S., Hansen, J., Nazarenko, L., and Luo, Y.: Climate effects of black carbon aerosols in China and India, Science, 297, 22502253, doi:10.1126/science.1075159, 2002.

Moorthy, K. K., Babu, S. S., and Satheesh, S. K.: Aerosol spectral optical depths over Bay of Bengal: role of transport, Geophys. Res. Lett., 30(5), 1249, doi:10.1029/2002GL016520, 2003.

Moorthy, K. K., Suresh Babu, S., and Satheesh, S. K.: Aerosol characteristics and radiative impacts over the Arabian Sea during the intermonsoon season: results from ARMEX field campaign, J. Atmos. Sci., 62, 192-206, 2005.

Moorthy, K. K., Satheesh, S. K., Babu, S. S., and Dutt, C. B. S.: Integrated campaign for aerosols, gases and radiation budget (ICARB): an overview, J. Earth Syst. Sci., 117, 243-262, 2008.

Moorthy, K. K., Nair, V. S., Babu, S. S., and Satheesh, S. K.: Spatial and vertical heterogeneities in aerosol properties over oceanic regions around India: implications for radiative forcing, Q. J. Roy. Meteorol. Soc., 135, 2131-2145, 2009.

Moorthy, K. K., Beegum, S. N., Babu, S. S., Smirnov, A., Rachel, S., John, Kumar, K. R., Narasimhulu, K., Dutt, C., and Nair, V. S.: Optical and physical characteristics of Bay of Bengal aerosols during W-ICARB: spatial and vertical heterogeneities in the MABL and in the vertical column, J. Geophys. Res., 115, D24213, doi:10.1029/2010JD014094, 2010.

Morys, M., Mims III, F. M., Hagerup, S., Anderson, S. E., Baker, A., Kia, J., and Walkup, T.: Design calibration, and performance of MICROTOPS II handheld ozone monitor and Sun photometer, J. Geophys. Res., 106(D13), 14573-14582, 2001.

Nair, V. S., Babu, S. S. and Moorthy, K. K.: Aerosol characteristics in the marine atmospheric boundary layer over the Bay of Bengal and Arabian Sea during ICARB: Spatial distribution, latitudinal and longitudinal gradients, J. Geophys. Res., 113, D15208, doi:10.1029/2008JD009823, 2008.

Nair, V. S., Moorthy, K. K., Babu, S. S., and Satheesh, S. K.: Optical and physical properties of atmospheric aerosols over the Bay of Bengal during ICARB, J. Atmos. Sci., 66, 2640-2658, 2009.

Nair, V. S., Satheesh, S. K., Moorthy, K. K., Babu, S. S., Nair, P. R., and George, S. K.: Surprising observation of large anthropogenic aerosol fraction over the "near-pristine" Southern Bay of Bengal: climate implications, J. Geophys. Res., 115, D21201, doi:10.1029/2010JD013954, 2010.

Ogunjobi, K. O., He, Z., Kim, K. W., and Kim, Y. J.: Aerosol optical depth during episodes of Asian dust storms and biomass burning at Kwangju, South Korea, Atmos. Environ., 38, 13131323, 2004.

Pace, G., di Sarra, A., Meloni, D., Piacentino, S., and Chamard, P.: Aerosol optical properties at Lampedusa (Central Mediterranean). 1. Influence of transport and identification of different aerosol types, Atmos. Chem. Phys., 6, 697-713, doi:10.5194/acp-6-697-2006, 2006.

Pathak, B., Kalita, G., Bhuyan, K., Bhuyan, P. K., and Krishna Moorthy, K.: Aerosol temporal characteristics and its impact on shortwave radiative forcing at a location in the northeast of India, J. Geophys. Res., 115, D19204, doi:10.1029/2009JD013462, 2010.

Porter, J. N. and Clarke, A. D.: Aerosol size distribution models based on in situ measurements, J. Geophys. Res., 102, 60356045, 1997.

Porter, J. N., Miller, M., Pietras, C., and Motell, C.: Ship based sun photometer measurements using Microtops Sun photometer, J. Atmos. Ocean. Tech., 18, 744-765, 2001.

Prasad, A. K., Singh, R. P., and Kafatos, M.: Influence of coal based thermal power plants on aerosol optical properties in the Indo-Gangetic Basin, Geophys. Res. Lett., 33, L05805, doi:10.1029/2005GL023801, 2006.

Prospero, J. M., Ginoux, P., Torres, O., Nicholson, S. E., and Gill, T.: Environmental characterization of global sources of atmospheric soil dust identified with Nimbus 7 Total Ozone Mapping Spectrometer (TOMS) absorbing aerosol product, Rev. Geophys., 40, 1, 1002, doi:10.1029/2000RG000095, 2002.

Rajeev, K., Ramanathan, V., and Meywerk, J.: Regional aerosol distribution and its long-range transport over the Indian Ocean, J. Geophys. Res., 105, 2029-2043, 2000.

Raghavendra Kumar, K., Narasimhulu, K., Balakrishnaiah, G., Reddy, B. S. K., Rama Gopal, K., Reddy, R. R., Reddy, L. S. S., Moorthy, K. K., Babu, S. S., and Dutt, C. B. S.: Spatial heterogeneities in aerosol properties over Bay of Bengal inferred from ship-borne and MODIS observations during ICARB-W cruise campaign: implications to radiative forcing, Atmos. Environ., 45(2), 404-412, 2011.

Ramachandran, S.: Spectral aerosol optical characteristics during the northeast monsoon over the Arabian Sea and the Tropical Indian Ocean: 2. Angstrom and anthropogenic influence, J. Geophys. Res., 109, D19208, doi:10.1029/2003JD004483, 2004.

Ramachandran, S.: Aerosol optical depth and fine mode fraction variations deduced from Moderate Resolution Imaging Spectroradiometer (MODIS) over four urban areas in India, J. Geophys. Res., 112, D16207, doi:10.1029/2007JD008500, 2007. 
Ramachandran, S. and Kedia, S.: Black carbon aerosols over an urban region: radiative forcing and climate impact, J. Geophys. Res., 115, D10202, doi:10.1029/2009JD013560, 2010.

Ramachandran, S. and Rajesh, T. A.: Black carbon aerosol mass concentrations over Ahmedabad, an urban location in Western India: comparison with urban sites in Asia, Europe, Canada and USA, J. Geophys. Res., 112, D06211, doi:10.1029/2006JD007488, 2007.

Ramanathan, V., Crutzen, P. J., Kiehl, J. T., and Rosenfeld, D.: Aerosol, climate and the hydrological cycle, Science, 294, 21192124, 2001a.

Ramanathan, V., Crutzen, P. J., Lelieveld, J., Mitra, A. P., Althausen, D., Anderson, J., Andreae, M. O., Cantrell, W., Cass, G. R., Chung, C. E., Clarke, A. D., Coakley, J. A., Collins, W. D., Conant, W. C., Dulac, F., Heintzenberg, J., Heymsfield, A. J., Holben, B., Howell, S., Hudson, J., Jayaraman, A., Kiehl, J. T., Krishnamurti, T. N., Lubin, D., McFarquhar, G., Novakov, T., Ogren, J. A., Podgorny, I. A., Prather, K., Priestley, K., Prospero, J. M., Quinn, P. K., Rajeev, K., Rasch, P., Rupert, S., Sadourny, R., Satheesh, S. K., Shaw, G. E., Sheridan, P., and Valero, F. P. J.: Indian Ocean experiment: an integrated analysis of the climate forcing and effects of the great Indo-Asian haze, J. Geophys. Res., 106, 28371-28398, 2001b.

Reddy, L. A. K., Kulshrestha, U. C., Satyanarayana, J., Kulshrestha, M. J., and Moorthy, K. K.: Chemical characteristics of $\mathrm{PM}_{10}$ aerosols and air mass trajectories over Bay of Bengal and Arabian Sea during ICARB, J. Earth Syst. Sci., 117, 345-352, 2008.

Reid, J. S., Eck, T. F., Christopher, S. A., Hobbs, P. V., and Holben, B. N.: Use of the Angstrom exponent to estimate the variability of optical and physical properties of aging smoke particles in Brazil, J. Geophys. Res., 104(D22), 27473-27489, 1999.

Remer, L. A., Kaufman, Y., Holben, B. N., Thompson, A. M., and McNamara, D. P.: Biomass burning aerosol size distribution and modeled optical properties, J. Geophys. Res., 103, 31879-31891, 1998.

Rosen, H., Hansen, A. D. A., Gundel, L., and Novakov, T.: Identification of the optically absorbing component in urban aerosols, Appl. Optics, 17, 3859-3861, 1978.

Satheesh, S. K. and Krishna Moorthy, K.: Radiative effects of natural aerosols: a review, Atmos. Environ., 35, 2089-2110, 2005.

Satheesh, S. K., Ramanathan, V., Jones, L. X., Lobert, J. M., Podrogny, I. A., Prospero, J. M., Holben, B. N., and Loeb, N. G.: A model for the natural and anthropogenic aerosols for the tropical Indian Ocean derived from Indian Ocean experiment data, J. Geophys. Res., 104(D22), 27421-27440, 1999.

Satheesh, S. K., Ramanathan, V., Holben, B. N., Moorthy, K. K., Loeb, N. G., Maring, H., Prospero, J. M., and Savoie, D.: Chemical, microphysical, and radiative effects of Indian Ocean aerosols, J. Geophys. Res., 107(D23), 4725, doi:10.1029/2002JD002463, 2002.
Satheesh, S. K., Moorthy, K. K., Kaufman, Y. J., and Takemura, T.: Aerosol optical depth, physical properties and radiative forcing over the Arabian Sea, Meteorol. Atmos. Phys., 91, 45-62, 2006.

Satheesh, S. K., Vinoj, V., Suresh Babu, S., Krishna Moorthy, K., and Nair, Vijayakumar S.: Vertical distribution of aerosols over the east coast of India inferred from airborne LIDAR measurements, Ann. Geophys., 27, 4157-4169, doi:10.5194/angeo-274157-2009, 2009.

Satheesh, S. K., Vinoj, V., and Krishna Moorthy, K.: Radiative effects of aerosols at an urban location in Southern India: observations versus model, Atmos. Environ., 44, 5295-5304, 2010.

Schuster, G. L., Dubovik, O., and Holben, B. N.: Angstrom exponent and bimodal aerosol size distributions, J. Geophys. Res., 111, D07207, doi:101029/2005JD006328, 2006.

Shaw, G. E.: Absorption continuum in the near IR near $1 \mu \mathrm{m}$, Appl. Optics, 19, 480-482, 1980.

Sinha, P. R., Manchanda, R. K., Subbaro, J. V., Dumka, U. C., Sreenivasan, S., Suresh Babu, S., and Moorthy, K. K.: Spatial distribution and vertical structure of the MABL aerosols over the Bay of Bengal during winter: results from W-ICARB experiment, J. Atmos. Solar Terr. Physics, 73, 4, 430-438, 2011 a.

Sinha, P. R., Manchanda, R. K., Kaskaoutis, D. G., Sreenivasan, S., Krishna Moorthy, K., and Suresh Babu, S.: Spatial heterogeneities in aerosol size distribution over Bay of Bengal during Winter-ICARB Experiment, Atmos. Environ., doi:10.1016/j.atmosenv.2011.04.085, in press, 2011 b.

Singh, R. P., Dey, S., Tripathi, S. N., Tare, V., and Holben, B.: Variability of aerosol parameters over Kanpur, Northern India, J. Geophys. Res., 109, D23206, doi:10.1029/2004JD004966, 2004.

Smirnov, A., Holben, B. N., Slutsker, I., Giles, D. M., McClain, C. R., Eck, T. F., Sakerin, S. M., Macke, A., Croot, P., Zibordi, G., Quinn, P. K., Sciare, J., Kinne, S., Harvey, M., Smyth, T. J., Piketh, S., Zielinski, T., Proshutinsky, A., Goes, J. I., Nelson, N. B., Larouche, P., Radionov, V. F., Goloub, P., Moorthy, K. K., Matarrese, R., Robertson, E. J., and Jourdin, F.: Maritime aerosol network as a component of Aerosol Robotic Network, J. Geophys. Res., 114, D06204, doi:10.1029/2008JD011257, 2009.

Venkataraman, C., Habib, G., Eiguren-Fernandez, A., Miguel, A. H., and Friedlander, S. K.: Residential biofuels in South Asia: carbonaceous aerosol emissions and climate impacts, Science, 307, 1454-1456, 2005.

Vinoj, V., Suresh Babu, S., Satheesh, S. K., Moorthy, K. K., and Kaufman, Y. J.: Radiative forcing by aerosols over the Bay of Bengal region derived from shipborne, island-based, and satellite (moderate-resolution imaging spectroradiometer) observations, J. Geophys. Res., 109, D05203, doi:10.1029/2003JD004329, 2004.

Wild, M.: Global dimming and brightening: a review, J. Geophys. Res., 114, D00D16, doi:10.1029/2008JD011470, 2009. 